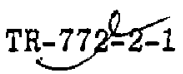

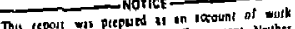

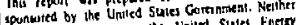
the "Iniled Sultes not the Uniled Stult Enern

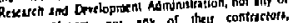

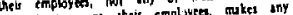

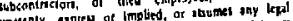

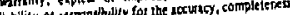

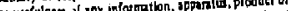

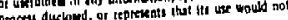

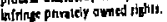

\title{
ANALYSIS OF NUCLEAR WASTE MANAGEMENT
}

\author{
S/C 9/63/05
}

31 October 1976

Prepared for:

THE UNIVERSITY OF CALIFORNIA Lawrence Livermore Laboratory Livermore, California

\author{
Prepared by \\ Julian L. Center \\ Bard S. Crawford \\ Benjamin Ross \\ Arthur A. Sutherland, Jr. \\ Approved by \\ Artiur Gelb
}

THE ANALYTIC SCIENCES CORPORATION

Six Jacob Way

Reading, Massachusetts 01867 


\section{FOREWORD}

The purpose of the effort reported here was to pexform a broad systems analysis of waste management, identify the most important modes of accidental release of radioactive material from high level solidified wastes and develop computer codes which can be instrumental in future, more detailed analyses. The work was performed by the authors and Alberto B. Calvo and Richard E. Mauch at TASC.

The authors acknowledge the support and cooperation of Thomas Holdsworth, Richard A. Van Konynenburg and Jerry Cohen at Lawrence Ljyermore Laboratory for their help and cooperation. 


\section{ABSTRACT}

An event tree is developed, outlining ways which radioactivity can be accidentally released from high level solidified wastes. Probabilities are assigned to appropriate events in the tree and the major contributors to dose to the general population are identified. All doses are computed on a per megawatt eleciric-year basis. Sensitivity relations between the expected dose and key characteristics of the solidified wasted are developed. 


\section{TABLE OF CONTENTS}

$\begin{array}{ll} & \text { Page } \\ \text { ABSTRACT } & \text { No. } \\ \text { List of Figures } & \text { iii } \\ \text { List of Tables } & \text { vi } \\ \text { vili }\end{array}$

1. INTRODUCTION 1-1

1.1 Background $1-1$

1.2 Overview $1-2$

1.3 Organization of the Report 1-3

2. MATHEMATICAL MODELS OF RELEASE 2-1

2.1 Functional Event Tree and General Assumptions 2-1

2.1.1 Functional Event Tree 2-1

2.1.2 General Assumptions 2-3

2.2 Handling at the Fuel Reprocessing Plant 2-4

2.2.1 Assumptions and Sources of Data 2-4

2.2.2 Event Tree 2-6

2.2.3 Calculation of Release Per Megawatt
Electric-Year

2.3 Interim High Level Solidified Waste Storage at

the Fuel Reprocessing Plant 2-10

2.3.1 Assumptions and Sources of Data 2-10

2.3.2 Event Tree 2-12

2.3.3 Calculation of Release Per Megawatt
Electric-Vear

2.4 Transportation $2-15$

2.4.1 Assumptions and Sources of Data 2-16

2.4.2 Event Tree 2-19

2.4.3 Nominal Maximum Release Fractions 2-24

2.4.4 Sample Calculations 2-25

2.5 Handling, Storage and Post Emplacement Period
at the Final Geologic Isolation Site

2.5.1 Assumptions and Sources of Data 2-27

2.5 .2 Event Tree $2-28$

2.5.3 Calculation of Release Per Megawatt
Electric-Year

2.6 Release After Sealing the Final Geologic
Isolation Site

2.6.1 Assumptions and Sources of Data 2-32

2.6.2 Event Tree 2-38

2.6.3 Methodology and Sample Calculations 2-38

$\begin{array}{ll}2.7 & \text { Chapter Sunmary } \\ 2-49\end{array}$ 


\section{TABLE OF CONTENTS (Continued)}

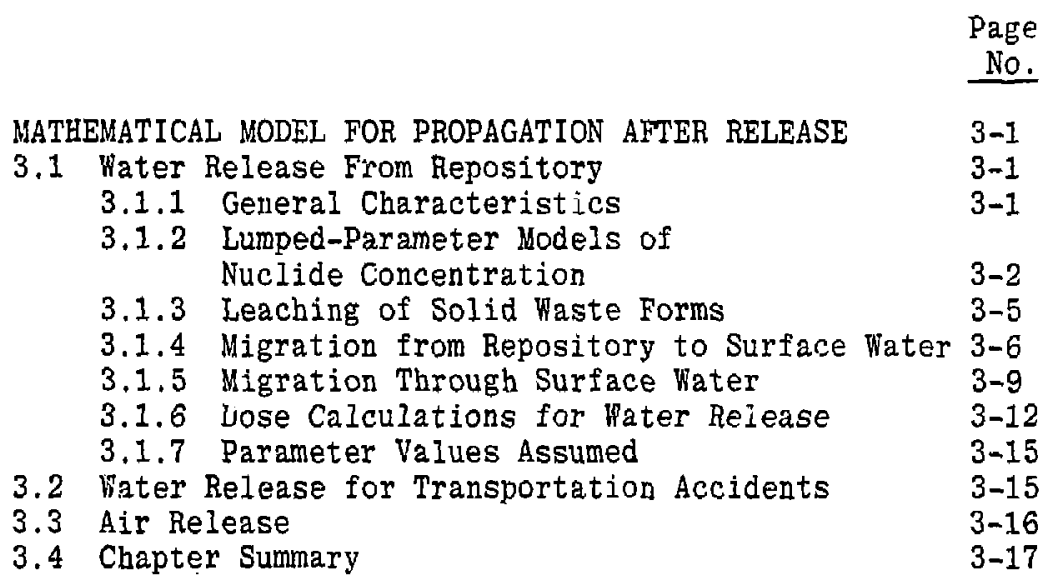

4. SENSITIVITY OF POPULATION IOSE TO CHARACTERISTICS OF HIGH LEVEL SOLIDIFIED WASTE

4.1 Sensitivity Analysis for the Pre-

Emplacement Period

4.2 Sensitivity Aralysis of the Post

Emplacement Period

$4-2$

4.3 Chapter Summary

5. CONCLUSIONS AND RECOMMENDATIONS

$5-1$

5.1 Conclusions

5.2 Recommendations

$5-1$

$5-2$

APPENDIX A CONCENTRATION EQUATIONS FOR THE AQUIFER A-1

APPENDIX B CONCENTRATION EQUATIONS FOR WATER, SOIL, AND PEOPLE

APPENDIX C EQUATIONS FOR NUCLIDE INTAKES

REFERENCES 


\section{LIST OF FIGURES}

Figure

Page

No.

No.

2.1-1 Functional Event Tree

2.2-1 Event Tree for Handling at the Fuel

Reprocessing Plant

$2-7$

2.3-1 Event Tree for Interim Storage in Water

2.4-1 Event Tree for Train Transportation Accident

2.4-2 Event Tree for Truck Transportation Accident

2.5-1 Event Tree for Handling at the Final Geologic Isolation Site

2.6-1 Final Geologic Isolation Geometry

2.6-2 Earthquake Frequency vs Magnitude

2.6-3 Event Tree: Pathways from the Final Geologic Isolation Site

2.6-4 Probability Flow Diagram Corresponding to Final Geologic Isolation Event Tree

2.6-5 Group Probabilities vs Time: Baseline Case

2.6-6 Group Probabilities vs Time: High

Seismic Activity

2.6-7 Group Probabilities vs Time: Low Seismic Activity

2.6 8 Group Probabilities vs Time: Better Administrative Control

3.1-1 Ground Water Migration Model

3.1-2 Mass Balance for Repository and Shaft 3-7

3.1-3 Mass Balance in Typical Aquifer Cell 3-8

3.1-4 Mass Balance for Last Aquifer Cell 3-8

3.1.5 Model for Surface-Water System 3-9

3.1-6 Mass Balance for Water 3-10

3.1-7 Mass Balance for Topsoil 3-10

3.1-8 Mass Balance for People 3-11

3.1-9 Mass Balaice for Sediment, Subsoil, etc. 3-11

4.1-1 Expected Dose as a Function of Release Fraction for Drainage of the Interim Storage Pool 


\section{LIST OF FIGURES (Continued)}

Figure

Page

No.

No.

4.1-2 Definition of Modal Accident

4.1-3 Sensitivity of Dose tu Solid Characteristics:

Transportation, Dispersion, Impact

4.1-4 Sensitivity of Dose to Solid Characteristics:

Transportation, Dispersion, Fire

4.1-5 Sensitivity of Dose to Solid Characteristics:

Transportation, Volatiles, Fire

4.1-6 Sensitivity of Dose to Solid Characteristics:

Transportation, Dispersion, Puncture

4.1-7 Sensitivity of Dose to Solid Characteristics: Transportation, Dissolution, Impact

4.1-8 Sensitivity of Dose to Solid Characteristics: Transportation, Dissolution, Fire

4.1-9 Sensitivity of Dose to Solid Characteristics: Trarsportation, Dissolution, Puncture.

4.2-1 Expected Value of Individual Dose From Release From the Repository

4.2-2 Expected Value of Individual Dose From Release From the Repository: Ion Exchange Process Inhibited 


\section{LIST OF TABLES}

Table

Page

No.

No.

2.4-1 Release Function End Points

2.4-2 Nominal Maxinum Release Fractions:

Transportation Accidents

2.6-1 Assumed Probabilities and Transition Rates For Final Geologic Isolation Tree

2.6-2 Discrete Joint Density Function For Initiating Event Times: Baseline Case

3.1-1 Parameters Values Assumed

4.1-1 Modal Accident Conditions 
1. INTRODUCTION

\subsection{BACKGROUND}

The regulation of nuclear waste management activities is one of the responsibilities of the U.S. Nuclear Regulatory Commission (NRC). The Lawrence Livermore Laboratory (LLL) is providing broad technical support to NRC in its efforts to establish a sound basis for development of regulations, criteria and standards in waste management. TASC is working under contract to LLL, and is helping to develop and apply quantitative systems analysis tools for the evaluation of alternative waste management options.

The current emphasis in these studies is centered on the handling and disposal of high-level solidified wastes (HLSW). The ultimate disposal sites (repositories) under current consideration are deep, geological formations in continental locations. Eventually other options, such as undersea disposal and the use of space vehicles to eject HLW material from the solar system, may also be considered.

High-level wastes are the most dangercus (radioactively and chenically) constituents of the residuals from reprocessing spent fuel elements from nuclear power plants. These constituents are fission products and the transuranic elements known as actinides -- having atomic number equal to or greater than actinium. Some of the latter have extremely long half-lives. For example, plutonium 239 has a half-life of 24,000 gears. 
The purpose of TASC's effort is to develop, for NRC and LLL, computer code representing all steps in high-level waste disposal. The code will be based on an event tree which delineates the different disposal methods, as well as unusual natural and man-made events which can thwart the intent of the disposal system. It will be capable of computing probabilities and consequences associated with all branches in the tree and converting these into various utility functions, most commonly related to dose to humans. The computer code is intenced to become a valuable aid in assessing alternative policies, criteria and standards.

\subsection{OVERVIEW}

The effort described in this report is the development of an initial event tree, mathematical modeling techniques associated with specific parts of the tree, and the generation of sample calculations. The computer code used to generate these calculations represents a useful learning device, from which the design of the ultimate code will arise.

A limited set of options, outlined in Section 2.1 , were considering in constructing the initial tree. The functional event tree of this report begins after the reprocessing stage and continues through possible releases from final geologic isolation, transport to the biosphere and dose to human beings. The following major phases are included:

\footnotetext{
- Handling at the fuel reprocessing plant (FRP)

- Storage at the FRP

- Transportation to the final geologic isolation site
} 
- Handling and storage at the final geologic isolation site

- Release after sealing the final geologic isolation site

Releases can occur during all of the above phases, and releases into both the air and surface and ground water are considered.

\subsection{CRGANIZATION OF THE REPORT}

A functional event tree is presented at the start of Chapter 2, outlining the major options and phases considered. The five major phases are then treated in detail in successive sections of the chapter. In each case assmptions and data sources are stated, followed by a detailed description of that portion of the tree and, finally, by a presentation of sample calculations. Mathematical models representing propagation after release are presented in Chapter 3 . Sensitivity analyses are summarized in Chapter 4. The purpose of these is to identify critical release mechanisms and to assess the impact of variations in critical parameters. Conclusions and recommendations are briefly outlined in Chapter 5. 
2. MATHEMATICAL MODELS OF RELEASE

\subsection{FUNCTIONAL EVENT TREE AND GENERAL ASSUMPTIONS}

\subsubsection{Functional Event Tree}

Figure 2.1-1 provides an overview of the major functional phases of the waste management system. Not all branches of the tree are shown, since there is considerable replication. At the top level is the decision as to what form and composition the waste material should take prior to handling, storage, transportation and final disposal. Alternative forms are indicated on the figure as "Baseline A", "Baselj.ne B", etc. The next level represents handling procedures to be used to move waste canisters from the reprocessing facility to the interim storage at the fuel reprocessing plant.

In this report storage in water-filled pools is treated. This is considered to be the most likely mode of interim storage. Other modes can be investigated in subsequent analyses. Transportation to the final site can involve one or multiple modes, including over-water stages by barge. In this report detailed consideration is restricted to train and truck transportation modes. Handling at the final site is also treated.

The history of the waste material after sealing of the final isolation site is examined in terms of a generic, baseline site. The final site is assumed, in this report, to be in a deep continental geological formation separated 


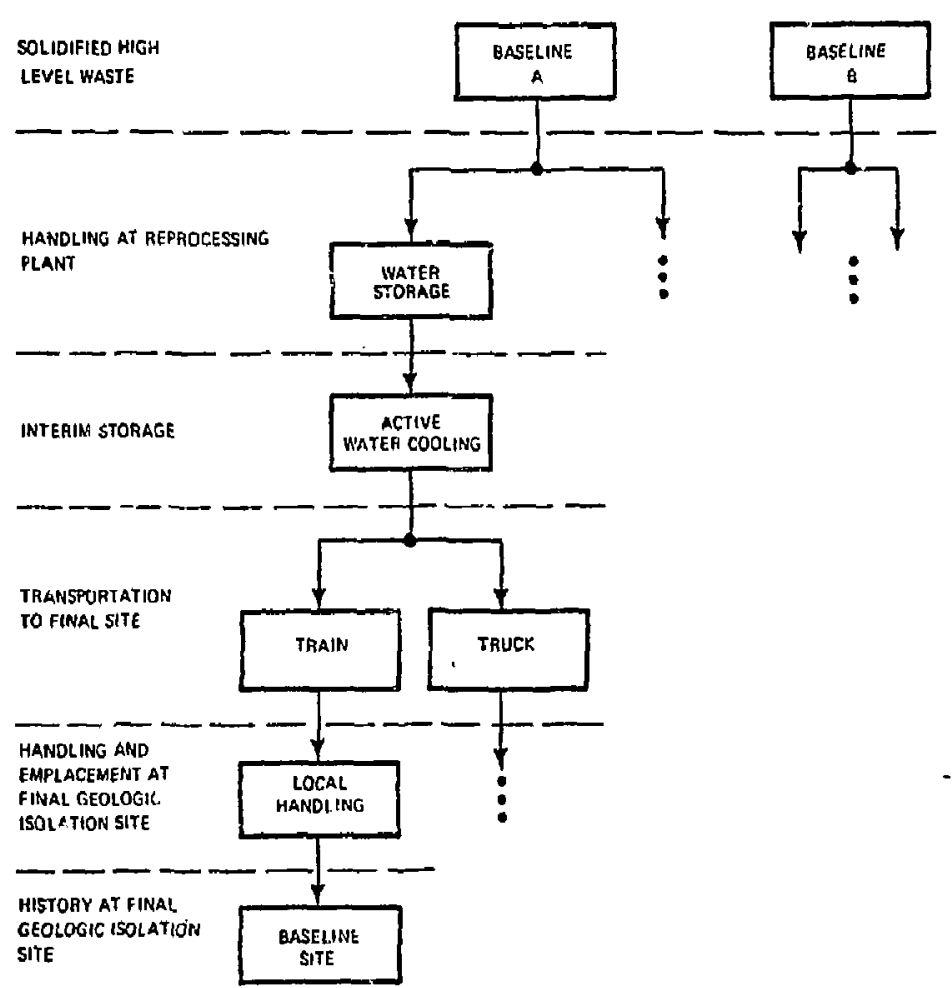

Figure 2.1-1 Functional Event Tree

from the shallow, ground-water-carrying lager (aquifer) by some form of impermeable barrier layer.

The simple calculations which follow determine the relative importance of each of the functional phases of the event tree shown in Fig. 2,1-1, in terms of expected material released and expected radiation dose to man, per megawatt electric-year. The emphasis is put on the major contributors to dose and the senstivities of their impact on man to solid raste form characteristics $s$ computed. 


\subsubsection{General Assumptions}

The following assumptions are used throughout the ancilyses described in subsequent sections of this report:

- Only solidified high level waste from co-partitioning raffinate is considered.

- Waste from mixed oxide fuei is not considered.

- Both uranium and plutonium are recovered (e.g., 99.5\% removal) at the fuel reprocessing plant, leaving $0.5 \%$ in the waste.

- Age of waste handled up to burjal ranges from 180 days to 10 years. Specifically, 1 and 10 years are used to delineate the effects of age prior to sealing of the repository.

- Interim storage of high level solidified waste (HLSW) occurs at the fuel reprocessing plant site.

- "Secondary" waste stream (contaminated equipment, etc.) is not a consideration.

- Events out to $10^{6}$ years from removal from the reactor are to be considered.

- No monitoring takes place at the final geological isolation site after emplacement.

- Two generic solidified waste forms are postulated: Baseline $A$ and Baseline $B$. The former is considered to have low thermal conductivity and high soluability, dispersibility and volatility. The latter is considered to have relatively high conductivity and low soluability, dispersibility and volatility. 


\subsection{HANDLING A'T THE FUEL REPROCESSING PLANT}

This section describes the calculations which determine the effect of accidental releases of high level nuclear wastes during handling at the fuel reprocessing plant (FRP). The accidents postulated are representative of those which can occur when numerous canisters of solidified waste are stored in a pool of water. Operations such as canister sealing, decontamination and testing were not specifically considered because they are conducted in-cell. The section concludes with a set of calculations whish demonstrate the relative unimportance of handling accidents at the FRP.

\subsubsection{Assumptions and Sources of Data}

The following assumptions are important in understalding the analytic event tree for handling at the interim storage site. Many of these assumptions are also key to the event tree for accidents which occur while the waste is in storage (see Section 2.3), They are not repeated in Section 2,3.

- Nominal canister size is $30 \mathrm{~cm} \times 3 \mathrm{~m}$. This will hold 0.2 cubic meters of 10-year old waste from 3.33 metric tons of LWR fuel. Exposure was $32,000 \mathrm{MWd} / \mathrm{MgU}$ at $35.4 \%$ efficiency. One canister holds the waste for 100 MWe-yr*

- In considering the impact of themal conductivity, time since removal from the reactor and volume of waste generated, use will be made of a basic first-order linearity in the

*Conversations with LLL personnel. 
model, Specifically, if twice as many canisters, rail cars, etc, are needed to handle the waste from 1 MVe-yr because of some driving parameter, then each can will have half as much radi oactive material (for a given time since removal from the reactor; therefore, while the provability of an accident doubles, the maximum radioactive material available for reiease in an accident balves. The only significant differences are those characteristics which determine the percent of available radioactivity released in a given accident mode.

- All operations in interim water storage of HLSW take place within a normally sealed building.

- A transfe: cask will be used to protect the sanister during most novement out of water. The cask is capable of protecting the can from overheat and damage due to drops. The only time the can is in danger is when it is outside the cask.

- Equipment will be arranged to prevent movement of the transfer cask over the water storage basin (precludes dropping the cask into the basin).

- Release does not occur if a canister dropped from the crane lands in the pool.

- The only mechanism for release into the sealed environment is that of an overheat and melting of the can and contents because it is required to remain in air ail out of the cask for an exceptionally I, ng time.

- The functioning air filtration system will pass $10^{-11}$ of all volatiles released from accidents within the plant.*

*Conversation with Mr. Mark Hanson, Battelle Pacific Northwest Labs. 
- The probability of filtration system failure is $10-6 / \mathrm{yr}$. "This is identical to the HEPA failure rate given in Ref. 1. The probability that filter failure will allow release of volatile materials from an accident withis the sealed builoing is based on the probability that the filter will fail within one week after the accident ( $\left.1 / 52 \times 10^{-6}\right)$.

- When the filter fails within one week of an accident, $1 \%$ of the volatiles released within the building escape into the atmosphere. The rest will condense inside the building.

- Nominal probability of crane drop is $3 \times 10^{-6}$ per hour of operation, obtained from Ref. 1.

- Nominal probability of crane stali is $1.5 \times 10^{-6}$ per hour of operation.

- The nominal time spent handling each canister $j n$ air outside the cask is 20 min. This includes time for insertion into the pool, retrieval and insertion in a transportation cask.

- Given a crane stall or drop outside the pool, the probability of overheat to melt is 0.5 for 1-yr old Baseline A waste, zero for 1-year old Baseline $B$ waste and zero for all 10-yr old waste.'

\subsubsection{Event Tree}

Figure 2.2-1 shows the event tree used to represent major accidental release modes for handling the solidified

*Conversation with Mr. Mark Hanson, Battelle pacific Northwest Labs.

**Conversation with Mr. Norman Smith, Materials Handling Institude

tSource, LLL. 


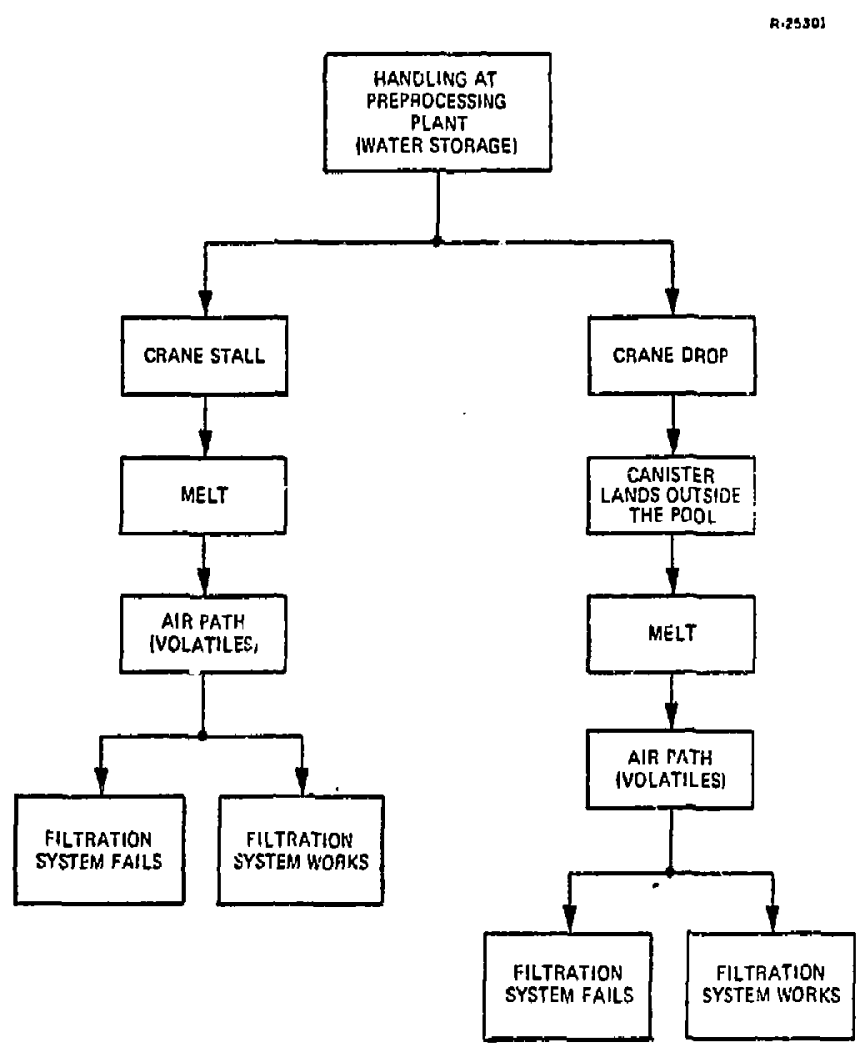

Figure 2.2-1 Fvent Tree for Handling at the Fuel Reprocessing Plant

waste at a water storage site. Consistent with the assumptions stated above, crane stall and crane drop when the canister is not over water are the two major accident modes.

\subsubsection{Calculation of Release Per Megawatt E'lectric-Year}

Using the assunptions and probabilities stated in Section 2.2-1 it is possible to compute expected values of waste released per MWe-yr. Note that no 10-yr old waste is released because the probability of canister breach is zero for that condition. In these calculations it is assumed that $100^{\circ}$ of the volatiles available (specifically $\mathrm{Ce}, \mathrm{Ru}$ and $\mathrm{Te}$ ) are 
re? eased into the building containing the pool. This assumption is used because it is shown that the expected release from handling accidents at the interim storase site are of no consequence relative to expected releases from other portions of the waste disposal tree; the effort required to develop release fractions (those fractions of available material actually released in a given accident) can be avoided hore, as may be noted from the following.

Crane Stall - Prograssing down the left side of the event tree shown in Fig. 2.2-1, the probasility of a crane stall accident, per canister of solidified waste is

$$
\left(1.5 \times 10^{-6} \frac{\text { stalls }}{\text { hr of operation }}\right)\left(\frac{1 \text { hr operation }}{3 \text { can }}\right)=5 \times 10^{-7} \frac{\text { stalls }}{\text { can }}
$$

Each nominal canister contains 100 MWe-yr of solid waste. Therefore there are $5 \times 10^{-9}$ stalls/Mlle-yr. Two possibilities ensue: If the filtration system works for one week after the accident $10^{-11}$ of the amount released will enter the atmosphere. Assuming 100\% of the volatiles available are released, the expected amount released per MWe-yr is $5 \times 10^{-20}$ times the activity in one canister (due to $100 \mathrm{MWe}-\mathrm{yr}$ of waste). ${ }^{*}$ If the filtration system fails in tise week following the accident $10^{-2}$ of the available material will be released. The probability of filter failure is

$$
\left(10^{-6} \frac{1}{\mathrm{yr}}\right)\left(\frac{1 \mathrm{yr}}{52 \text { weeks }}\right)=1.92 \times 10^{-8} \frac{1}{\text { week }}
$$

\footnotetext{
*Strictly speaking this must be multiplied by one minus the probability of filter failure. It is easy to see that to a very good approximation that the number is unity.
} 
The expected amount released due to crane stall accidents followed by filter failure (1-yr old waste only) is then

$$
\left(5 \times 10^{-9}\right)\left(10^{-2}\right)\left(1.92 \times 10^{-8}\right)=9.5 \times 10^{-19} \frac{1}{M W e-y r}
$$

times the activity in one canister. Note that this is not much larger than the expected release from crane stall accidents where the filter does not fail.

The net expected release for the crare stall accident is the sum of the above two numbers -- e.g., $10^{-18}$ times the activity contents of one nominal canister. It can be seen that this is very small relative to comparable expected release computed for storage and transportation accidents. Differences in population distribution used in dose calculations cannot alter this conclusion.

\section{Crane Drop - A similar sequence of calculations} yields the expected release for a crane drop accident. The result is quickly obtained by noting that the probability of a crane drop is twice that of a stall while the probability of a canister failure given a drop is half that of a stall; all other numbers in the calculation are the same. Consequently the expected release due to a crane drop accident is the same as for a crane stall accident: $10^{-18}$ times the activity of the contents of one nominal canister.

It is concluded that handling accidents at the interin storage site do not contribute more than a very minor portion of the nominal expected dose from high level nuclear waste disposal. 


\subsection{INTERIM HIGH LIVEL SOLIDIFIED WASTE STORAGE AT THE FUEL REPROCESSING PLANT}

This section describes the calculations which determine the results of accidental releases of high level waste during storage in a pool of water. The wastes are assumed to be cooled by water convection. The water, in turn, is assuned to be cooled by an external mechanism such as cooling towers, etc. The key feature is t:at active cooling of the water is required for normal operation. Note that all probabilities computed in this section are stated per year of storage and must at some time be multiplied by an assumed period of storage.

\subsubsection{Assumptions and Sources of Data}

The following assumptions are important in understanding the analytic event tree jor interim storage. These are in addition to many assumptions already stated in Section 2.2.

The canisters are assumed to be stored many to a pool. The exact number per pool is not important, but the it is assumed to be sufficiently large that when cooling water is absent for a long time some of the canisters will fail. The mechanism for failure is assumed to involve coheating through radiation in the empty pool.

When absence of water is caused by loss of circulation, the canisters fail with probability 1 for 1-yr old Baseline A waste, 0.5 for $1-y r$ old Baseline $B$ waste and zero for 10-yr old waste. When absence of water is caused by pool draining due to a failure of the pool structure the corresponding probabilities are $1,0.6$ and 0.1 respectively. 
These are a little higher because the event causing the pool structure to fail can rearrange the cans and aggravate the self-heating.

Tornados and hurricanes are assumed to be no danger to the pool, which is below grade and strong enough to withstand impacts of missiles from these causes, Heteors are taken to be extraordinary occurrences of too small a probability to be analyzed.

- Earthquakes and aircraft crashes are assumed to be the most serious probable causes of cooling pool drainage. In both cases the event causing drainage will also cause rupture of the air seal which protects against release into the atmosphere.

- In the case of an earthquake it is asslimed that restoration of water cooling in any form before the canisters in the pool melt is prevented.

- In the case of an aircraft accident the probability of restoration of water cooling (e.g., hoses played on the waste) before the canisters melt is assumed to be 0.9 . This reflects the fact that the aircraft accident is a more local phenomenon, leaving water supplies intact.

- In all cases the water pathway for release into the environment is ignored because other calculations show that the consequences are minimal as long as there is a reasonable distance from the pool to the nearest surface water body. Also, a possibility for cleanup exists.

When the sealed building enclosing the pool remains intact the filter system considerations and probabilities stated in Section 2.2.1 operate. These will not be restated bere. 
- The nominal probability of a loss of active cooling of the pool water is 10-1/yr (Ref. 1). The probability that loss of cooling cannot be corrected before the contents of the pool boil off is 10-6 (Ref. 1).

The density of aircraft accidents is computed from Ref. 1 . There $j t$ is stated that $10^{-6}$ to $10^{-7}$ crashes are expected per year within a 5 mile radius of airports. Allowing for the fact that the interim storage site will far from busy airports, a frequency of $10-8 / \mathrm{yr}$ in a 5 mile radius is used to calculate a density of $1.27 \times 10^{-10}$ crashes/yr mi2.

A nominal storage pool is assumed to present an area of $2500 \mathrm{yd}^{2}$ or $8.07 \times 10^{-4} \mathrm{mi}^{2}$ to the possibility of an aircraft crash.

- The probability of having a severe earthquake (see Section 2.6 for definition) away from tectonic plate boundaries is $10^{-5} / \mathrm{yr}$ (Ref. 2).

- Given that the storage pool is designed to withstand a severe earthçuake, the probability of pool drainage resulting is 0.1 , given a severe earthquake.

- An aircraft crash may breach some cans in the pool. However, the major mechanism for release is pool drainage. The fire from the aircraft's fuel extinguishes itself before the pool empties enough to allow release of dispersable waste fractious.

- The population distribution assumed in calculating dose due to waste material released from interim storage into the atmosphere represents the population distribution at Barnwell, S.C.

\subsubsection{Event Tree}

Figure 2,3-1 shows the event tree for major modes of accidental release of nuclear waste from interim storage in water. 


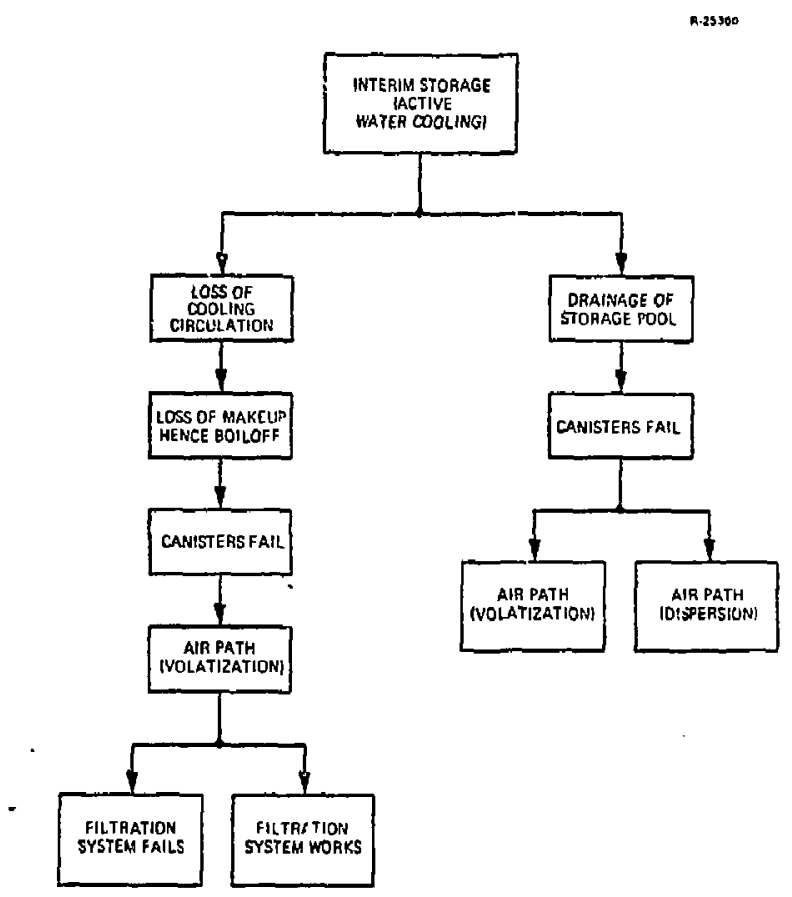

Figure 2.3-1 Event Tree for Interim Storage in Water

\subsubsection{Calculation of Release Per Megawatt Electric - Year}

Loss of Cooling Circulation - A calculation following the left side of the event tree is useful to show that the loss of cooling circulation accident is not a major contributor to the total expected dose from waste disposal operations.

Using the probabilities stated in the assumptions above, the expected frequency of occurrence of loss of cooling circulation and boilof of the cooling water is $\left(10^{-1}\right)\left(10^{-6}\right) 1 / \mathrm{yr}=10^{-7} 1 / \mathrm{yr}$. Given a boiloff, 1-yr old Baseline A waste will heat up to the point where the canister 
fails and releases volatiles (Cs, Ru and Te). Assuming for the moment that all volatiles available will be released, the expected activity within the building enclosing the pool is $10^{-7}$ of the activity available in the volatiles generated by one MWe-yr, per MPe-yr, per year of storage. Folloring a line of reasoning similar to that described in Section 2.2 for crane stall, if the filtration system works the above number is reduced by 11 orders of magnitude before entering the atmosphere. The probability of the filtration system failing in the week following boiloff is $1.92 \times 10^{-8}$ and, if the system fails, $10^{-2}$ of the available volatiles will be released into the atmosphere. The expected release from the accident sequence -- circulation fails, boiloff, filter fails in one week - is $1.92 \times 10^{-17}$ of the volatiles generated by one MWe-yr, per MWe-yr, per year of storage. This adds with $10^{-18}$ for the case when the filter does not fail. The maximum anticipated storage period of 10 years will give an expected release from this mode of $2 \times 10^{-16}$ of the volatiles available from one MWe-yr, per MWe-yr. (Recall that all these numbers assume a $100 \%$ relesse fraction.) It can be seen that the expected release is very small compared to those frum transportation and the pool drainage accident discussed subsequently.

Drainage of the Storage Pool - The accident involving drainage of the interim storage pool can be a major contributor to the expected dose from solidified waste disposal activities. Also, because the accident can typically involve a large amount of waste it can provide high individual doses to persons in the vicinity. As stated previously, two accident causes are considered to be possible contributors to this release moie - earthquakes and aircraft crashes. The aircraft crash density and pool area described in the above assumptions are lised to compute an expected aircraft accident frequency: 


$$
\left(1.27 \times 10^{-10} \frac{\mathrm{crashes}}{\mathrm{yr} \mathrm{mi}}\right)\left(8.07 \times 10^{-4} \mathrm{mi}^{2}\right)=1.02 \times 10^{-13} \frac{\mathrm{crashes}}{\mathrm{yr}}
$$

When one considers the probability of pool drainage from earthquakes, computed from the assumptions, of $10^{-6} / \mathrm{yr}$ it can be seen that the aircraft crash is of negligible significaut compared to seismic events as a cause of pool drainage.

\begin{abstract}
The kuy figure is then $10^{-6} / \mathrm{yr}$, which is the maximum expected fraction of nne MWe-yr's worth of waste that will be released per Mpe-yr, per year. This number must be multiplied by the release fractions given in section 2.3.3, the duration of storage, and the appropriate activity levels, depending on the age or ages of the waste assumed to be in the cooling pool, to obtain the expected amount of activity released per MWe-yr.
\end{abstract}

\title{
2.4 TRANSPORTATION
}

In computing probable releases of radioactive materials and the resultant dose, two modes of transportation were given primary consideration -- train and truck. Other means such as barges, can be considered at a later time, if necessary.

The current investigation relied heavily on the contents of Ref. 3 , keeping in mind that the problem at hand involves large transportation casks rather than the small packages which were of primary interest there. Conversations with personnel at Sandia and Battelle Pacific Northwest Laboratories as well as Refs. 4 through 6 were used as supplementary sources of data. 


\subsubsection{Assumptions and Sources of Data}

General - The following assumptions pertain to both train and truck accidents.

- No special transportation procedures are followed. Accident statistics for normal freight operations apply. This is conservative.

- Crush is not a factor for the massive transportation casks involved. Impact, fire and puncture are considered (Ref. 3 ).

- Immersion is considered an extraordinary event (Ref. 1) -- e.g., of low probability and/or consequence.

- Transportation casks are designed to meet "Type B" standards (Refs, 7 and 8). Specifically, impact: $30 \mathrm{ft}$ drop onto unyielding surface; fire, 44,250 oF-min; puncture, $V / R$ of $58 \mathrm{sec}^{-1}$.

- Canisters offer inconsiquential protection in transportation accidents, relative to the transportation casks. Therefore, if the cask is breached the cannisters are assumed to be breached also.

- The transportation casks are assumed to rely on passive convection air cooling to maintain satisfactory temperatures in the waste caiisters.

- The nominal transportation distance from interim storage to final disposal is 2000 miles.

- In computing dosage from release of radioactive materials, transportation accidents were assumed to take place with equal probability in urban and rural areas.

- Given an accident, a water pathway (rain, ditch, stream or river) is present $1 \%$ of the time. For fire accidents, water played on the fire should prevent the time-temperature product from reaching the value at vinich structural damage occurs or seals fail. 
- Given an impact or puncture accident, an air dispersion energy source is present $10 \%$ of the time.

- An air dispersion energy source (firestorm) is always present for a fire of size sufficient to effect the cask.

Train - The following assumptions and sources of data pertain specifically to train accidents:

- The nominal rail transportation cask will hold nine of the nominal canisters.

- The frequency of rail accidents is given in Ref. 3 as $1.37 \times 10^{-6}$ cai-accidents/ car mile.

- Due to speed limits, no urban train accidents occur at speeds above $40 \mathrm{mph}$. Half of all accidents below $40 \mathrm{mph}$ occur in urban areas.

- Only impacts with "extremely rigid" fixed objects will impose sufficient energy to breach the cask (see Ref. 3). The nominal probability of this kind of accident is computed from Ref. 3 as 0.051 per car accident.

- In an impact accident the cask is assuned to have the same velocity as the train and all the cask's resultant kinetic energy is dissipated on the cask.

- Table III, Vol. IV of Ref. 3 provides the velocity distributions for fixed object collisions.

- The probability of a fire, given a rail accident has occurred, is given in Ref. 3 as 0.059 . This is modified downward by a factor of 0.625 to account for the fact that for the case at hand no other cargo is carried on the same car.

*Telephone conversation with A. Dennis, Sandia. 
- The probability of puncture encuunter, given a train accident, is given as 0.546 in Ref. 3. The probability distribution for puncture accident severity is given in Fig. 28 (Assumption B) of Vol. IV, Ref. 3.

- A rail puncture accident involves 2 of the 9 canisters in the cask.

Truck - The following assumptions and sources of data pertain specifically to truck accidents:

- The nominal truck transportation cask will hold two of the nominal solid waste canisters.

- Only impact with "extremely rigid" fixed objects and crossing accidents with trains will impose sufficient energy to breach the cask (Ref. 3).

- Probabilities for these impact events, given an accident, are computed from Ref. 3 as 0.051 and 0.0062 , respectively.

- The probability of a crossing accident is reduced to 0.0031 to account for the fact that major energy is dissipated on the cask only when the locomotive frame impacts it.*

- In impact accidents all the energy provided by the truck (train) velocity is dissipated on the cask.

- The velocity distributions for fixed object collisions and crossing accidents are given in Fig. 4, Vol. III and Table II, Vol. IV of Ref. 3, respectively.

- Probability of a fire, given a truck accident is given in Ref. 3 as 0.016 . This probability is reduced by a factor of 0.625 to account for the fact that no other cargo is carried.*

*Telephone conversation with A. Dennis, Sandia. 
- The probability of a puncture encounter, given a truck accident, is computed from information given on $P .80$ of Vol. III, Ref. 3 to be 0.2 . The probability distribution for severity is given in Fig. 45 , Vol. III, Ref. 3.

- A truck puncture accident involves one of the two canisters in the cask.

The use of the above assumptions, probabilities and probability distribution will be explained further in the following sections.

\section{4 .2 Event Tree}

Train - Figure 2.4-1 shows the event tree used to represent release of nuclear waste materials from train accidents. The three major transportation accident modes -- impact, fire and puncture -- are shown, along with a fourth category, extraordinary occurrences. The probability and consequences of the latter mode were defined to be negligible.

It is instructive to revien the impact mode in detail. only collision with extremely rigid objects is considered, as stated in the preceding set of assmptions. A probability density function (pdf) for accidents was derived from the source cited above. Figure 2,4-1 represents the pdf as a continuous function of velocity; the representation in the figure is conceptual since the data available only permits calculation of constant pdf's over $10 \mathrm{mph}$ intervals.

Below the probability density function for impact velocity with extremely rigid objects is a representation of the weighting of the amount of material released as a function of accident severity. The Type $B$ cask is designed to 


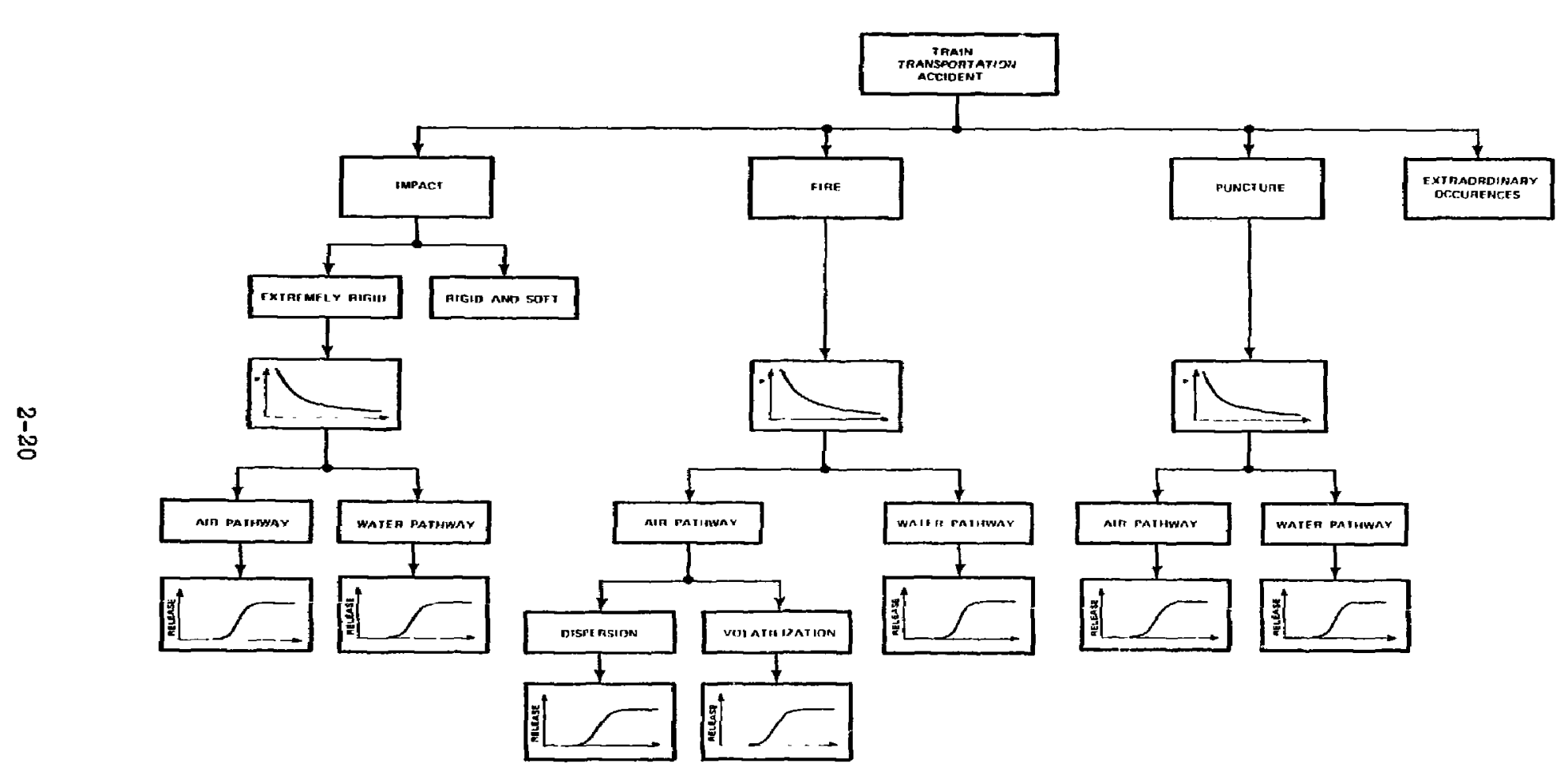

Figure 2.4-1 Event Tree for Train Transportation Accident 
withstand a $30 \mathrm{ft}$ drop onto an unyielding surface. This is equivalent to a $30 \mathrm{mph}$ collision with an unyielding surface. The release functions used in this study do not represe:t any release for collisions at velocitias below the cask design value. A typical release function, shown in the figure, allows the fraction of material to grow to a maximum value at $90 \mathrm{mph}$. The function is represented analytically by

\begin{tabular}{c|c} 
Fraction of Maximum Release & Velocity (mph) \\
\hline 0 & $V \leq 30$ \\
$\frac{1}{2}\left(1-\cos \frac{V-30}{60} \pi\right)$ & $30<\mathrm{V}<90$ \\
1 & $90 \leq \mathrm{V}$
\end{tabular}

The maximum release fraction is a function of the characteristics of the solid waste form. It can be specified in terms of a constant which multiplies the values computed from the event tree.

The sinape of all the release functions used in analysis of transportation accidents is the same as that discussed above. Only the end points of the curve change with accident mode and transportation mode (truck or train). Table 2.4-1 gives the end points for the "S-curves" of release functions. The values result from a sequence of conversations with LLL.

Figure 2.4-1 distinguishes the major pathways for the released radioactive material. The primary distinction is between water and air pathways. For the fire accident, the latter is further separated into dispersion and volatization modes of release because the release function used can be different for these two pathways.

Truck - Figure 2.4-2 shows the event tree used to analyze release of nuclear waste materials from truck acciaants, 


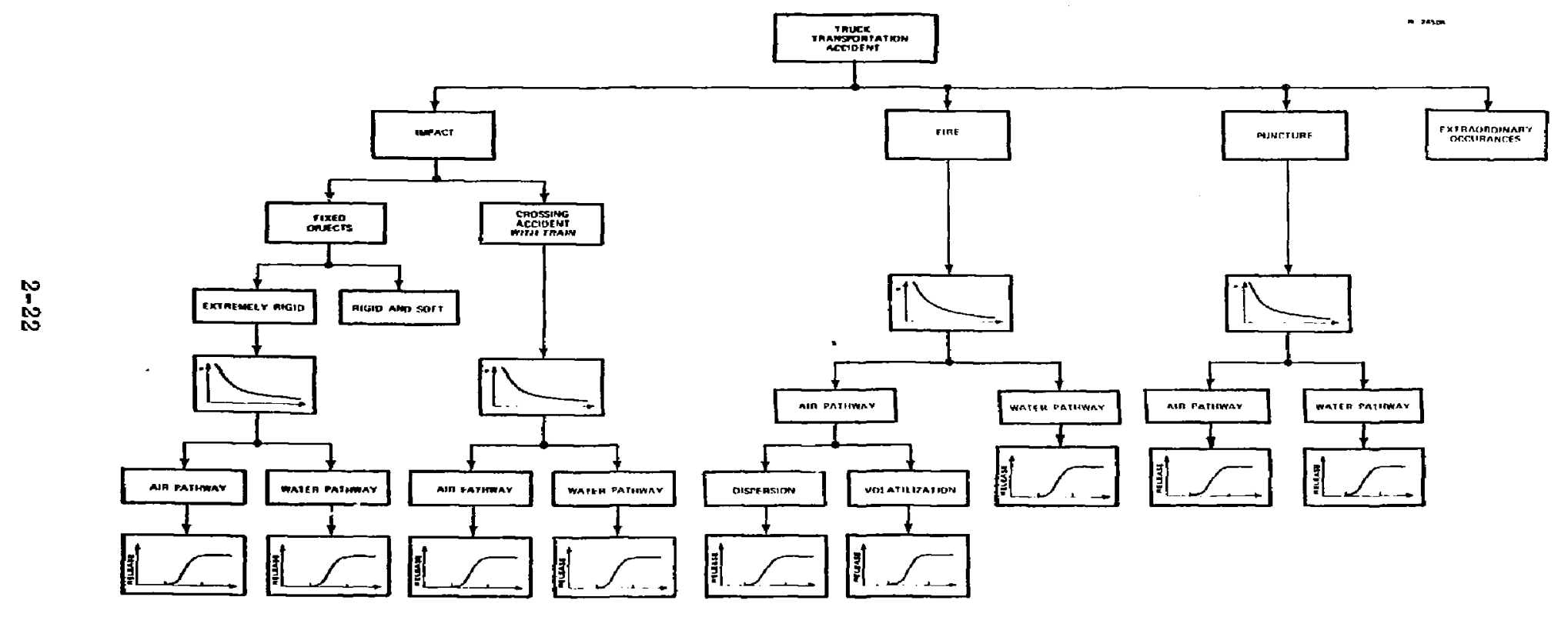

Figure 2.4-2 Event Tree for Truck Transportation Accident 
TABLE $2.4-1$

RELEASE FUNCTION END POINTS

$\mathrm{T}-0587$

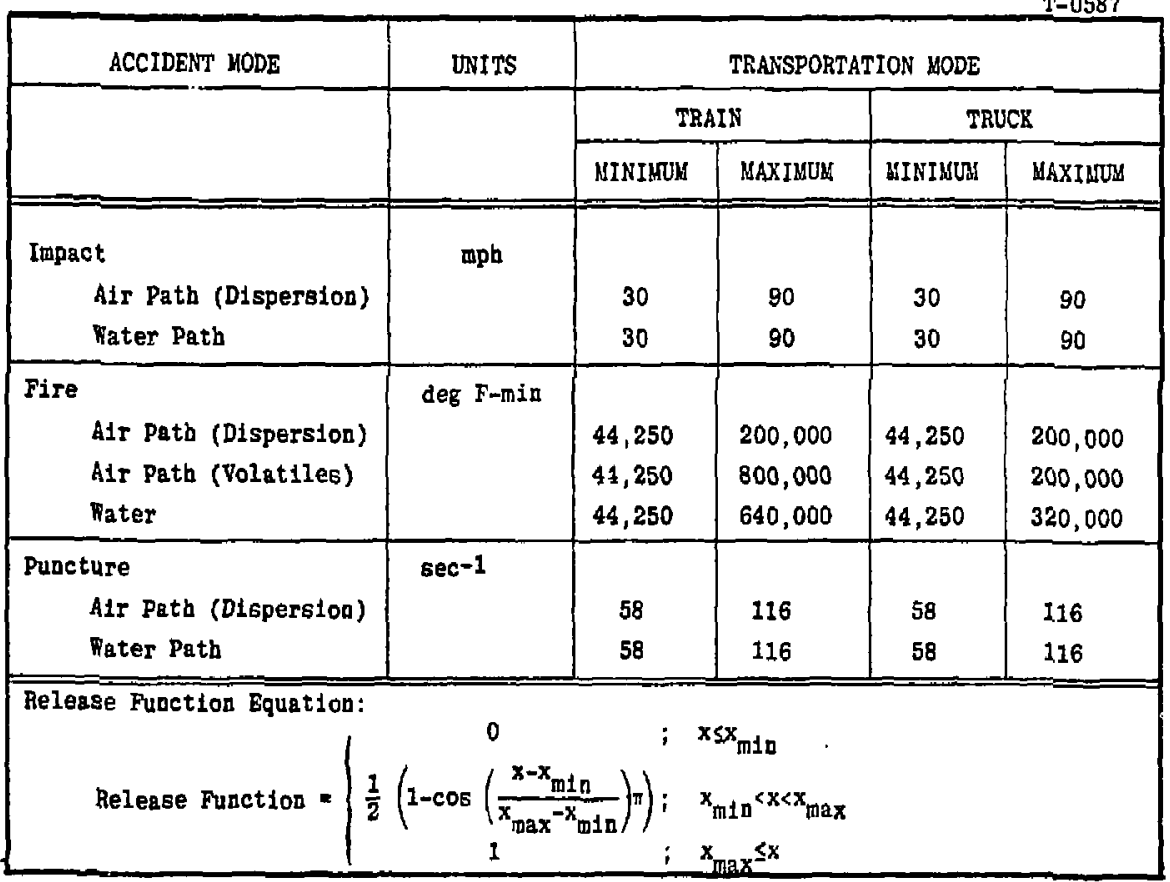

In accordance with the assumptions stated above, the structure of this tree differs from that for the rail accident primarily in describing the impact mode. Specifically the crossing accident, in which the truck is hit by a train, is added to this portion of the tree. Release functions are given in Tabie 2.4-1. In some cases the upper ends of the "S-curve" are at lower values of tive temperature-time product for the truck accident than for the train. This reflects the fact that the rail transportation cask is considerably more massive than that used with the truck and therefore the former can withstand a considerably large heat input before heing effected enough to permit release. 
The transportation accident event trees, when combined with numbers for the maximum release fraction, permit calculation of the expected release per megawatt electric-year.

\subsubsection{Nominal Maximum Release Fractions}

The choice of maximum release fractions is based on best engineering judgement. Table 2.4-2 gives the nominal maximum release fractions used in studying the effect of transportation accidents. The numbers shown reflect the characteristics of the Baseline $A$ and Baseline $B$ solids in terms of particle size, volatility and soluability in water. They also represent ithe assumed probabilities of the existence of air and water pathways which were stated in the preceding section, and an assumption that the solid waste is available for leaching for one fuli day where the water pathway is concerned.

TABLE $2.4-2$

NOMINAL MAXIMUM RELEASE FRACTIONS: TRANSPORTATION ACCIDENTS

\begin{tabular}{|l|l|c|c|}
\hline \multirow{2}{*}{ ACCIDENT } & \multicolumn{2}{|c|}{$\begin{array}{c}\text { MAXIMUM FRACTION } \\
\text { AVAILABLE }\end{array}$} \\
\cline { 2 - 4 } & $\begin{array}{c}\text { BASELINE } \\
\text { A }\end{array}$ & $\begin{array}{c}\text { BASELINE } \\
\text { B }\end{array}$ \\
\hline \hline Impact & $\begin{array}{l}\text { Air } \\
\text { (Dispersion) } \\
\text { Water }\end{array}$ & $10^{-2}$ & $10^{-6}$ \\
\hline Fire & $\begin{array}{l}\text { Air } \\
\text { (Dispersion) } \\
\text { Air } \\
\text { (Volatiles) }\end{array}$ & $10^{-2}$ & $3 \times 10^{-7}$ \\
\hline $\begin{array}{l}\text { Water } \\
\text { Puncture }\end{array}$ & $\begin{array}{l}\text { Air } \\
\text { (Dispersion) } \\
\text { Water }\end{array}$ & $3 \times 10^{-2}$ & $10^{-8}$ \\
\hline
\end{tabular}


It is beyond the scope of the present study to model the release of radioactive materials in further detail. During a subsequent effort it may be constructive to model in considerable detail the effect of accidents on cask and can structure, heat transfer, and concentrations in air and water pathways.

\subsubsection{Sample Calculations}

To illustrate the calculations which yield the expected value of the number of curies of a particular nuclide released per MHe-yr, we will concentrate on the release into the air of Baseline $A$ solid in a urban rail accident, impact mode. The air dispersion pathway and 10-year old waste vill be assumed.

Using the nominal canister, holding 100 MWe-yr of waste, and the nominal rail transportation cask holding nine canistars, each rail car holds 900 MWe-yr of waste. Using a nominal transportation distance of $2,000 \mathrm{mi}$ the number of car-miles per Mfe-yr is computed:

$$
\left(\frac{1 \mathrm{car}}{900 \mathrm{me}-\mathrm{yr}}\right)(2,000 \mathrm{mi})=2.22 \frac{\mathrm{car} \mathrm{mi}}{\mathrm{nTe}-\mathrm{yr}}
$$

The nominal accident frequency is $1.37 \times 10^{-6}$ car accidents/car mile. Therefore, the expected number of rail car accicients per Mife-yr is computed:

$$
\left(1.37 \times 10^{-6} \frac{\text { car accidents }}{\text { car mile }}\right) \quad\left(2.22 \frac{\mathrm{car} \text { mile }}{\text { MWe-yr }}\right)=3 \times 10^{-6} \frac{\text { car accidents }}{\text { WWe-yr }}
$$

The integral of the product of the accident severity probability density function and the release function (illustrated in Fig. 2.4-1) for the impact accident, is $9.23 \times 10^{-4}$. 
The probability of an impact with an extremely rigid object, given a rail accident has occurred, is $5.1 \times 10^{-2}$. Multiplying the expected number of car-accidents/MWe-yr by these two numbers yields $1.41 \times 10^{-10}$. This is the expected number of car-accidents/per MWe-yr which involve urban impact on extremely rigid object, weighted by the accident severity and the release function. To compute the expected amount of material released per MWe-yr this number must be multiplied by the appropriate maximum release fraction $\left(10^{-2}\right.$ in this example) and the amount of material carried on a single rail car, using the nominal can and cask designs. Thus the expected release per MWE-yr is

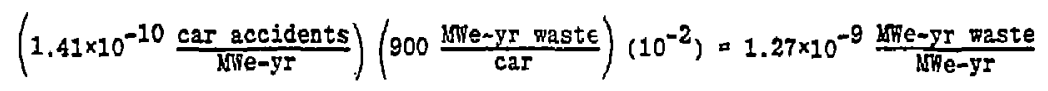

For 10-year old waste, 1 MHe-yr of waste contains $1.9 \times 10^{3}$ curies of ${ }^{90} \mathrm{Sr}$. Therefore the expected release into the air of ${ }^{90} \mathrm{Sr}$ from impact mode rail accidents, $10-\mathrm{yr}$ old Baseline $\mathrm{A}$ waste, is

$$
\left(1.27 \times 10^{-9} \frac{M W e-y r \text { waste }}{M W e-y r}\right)\left(1.9 \times 10^{3} \frac{C i}{M W e-y r}\right)=2.4 \times 10^{-6} \frac{C i}{M W e-y r}
$$

In a similar manner other release quantities can be computed on the basis of the nuclide of interest, accident mode, age of waste, solid characteristics and method of migration into the biosphere. 


\subsection{HANDLING, STORAGE AND POST EMPLACEMENT PERIOD} AT THE FINAL GEOLOGIC ISOLATION SITE

This section describes the calculations which establish the effect of accidental releases of high level nuclear wastes between the time the waste material arrives at the final geologic isolation site until the repository is sealed. It is shown that the expected release from this portion of the waste disposal operation is relatively unimportant compared to that from interim storage and transportation.

\subsubsection{Assumptions and Sources of Data}

The following assumptions were used in analyzing this portion of the waste disposal sequence:

- The head of the repository shaft is contained within a sealed building. Under normal conditions any contamination escaping into the ajr in this building is prevented from entering the atmosphere by a filtration system. The key filtration system parameters (probability of failure, efficiency) are identical with those used in analyzing the interim storage portion of the waste disposal operation (see Section 2.2)

- Transportation vehicles will enter the sealed storage area for unloading. The canisters will not be removed from their transportation casks until they are inside the building and the air seal is reestablished.

- $\quad$ S1 movement of the waste canisters between the transportation cask and their final underground location will take plaise in a transfer cask. The only time the cans will be bare is during transfer between casks and while they are being lowered into the floor of the repository. 
- At this point in the sequence of disposal events bare canisters can dissipate all heat generated into air. Therefore, the danger to the integrity of the canister during handling is from impact when accidentally dropped.

- The nouinal time the canister is outside the casks is 10 min per can. This includes movement between transportition cask and transfer cask and between transfer cask and the final location.

- The probability of crane drop is the same as in the analysis of iandling at interim storage $-3 \times 10^{-6}$ per hour of operation.

- The principal danger to the canisters while waiting to be lowered into the repository is from impact from an aircraft. The casks will protect against all other dangers such as earthquake, tornado, etc. Meteors are an extraordinary occurrence and were not analyzed. The same probabilities of aircraft crash density as used in Section 2.3 apply here.

- The transportation cask remains on the surface at the final site for a nominal period of 1 week before it is unloaded. This is the period of exposure to an aircraft impact.

- The water path for released wastes was not analyzed in detail. It is known from the other analyses that this will not be significant for releases in this portion of the disposal process if normal precautions are taken to avoid a direct path into surface water bodies serving large populations. The opportunity for cleanup also exists.

\section{5 .2 Event Tree}

Figure 2.5-1 shows the event tree analyzed to determine the consequences of accidental release during handling at the final geologic isolation site. In keeping with 


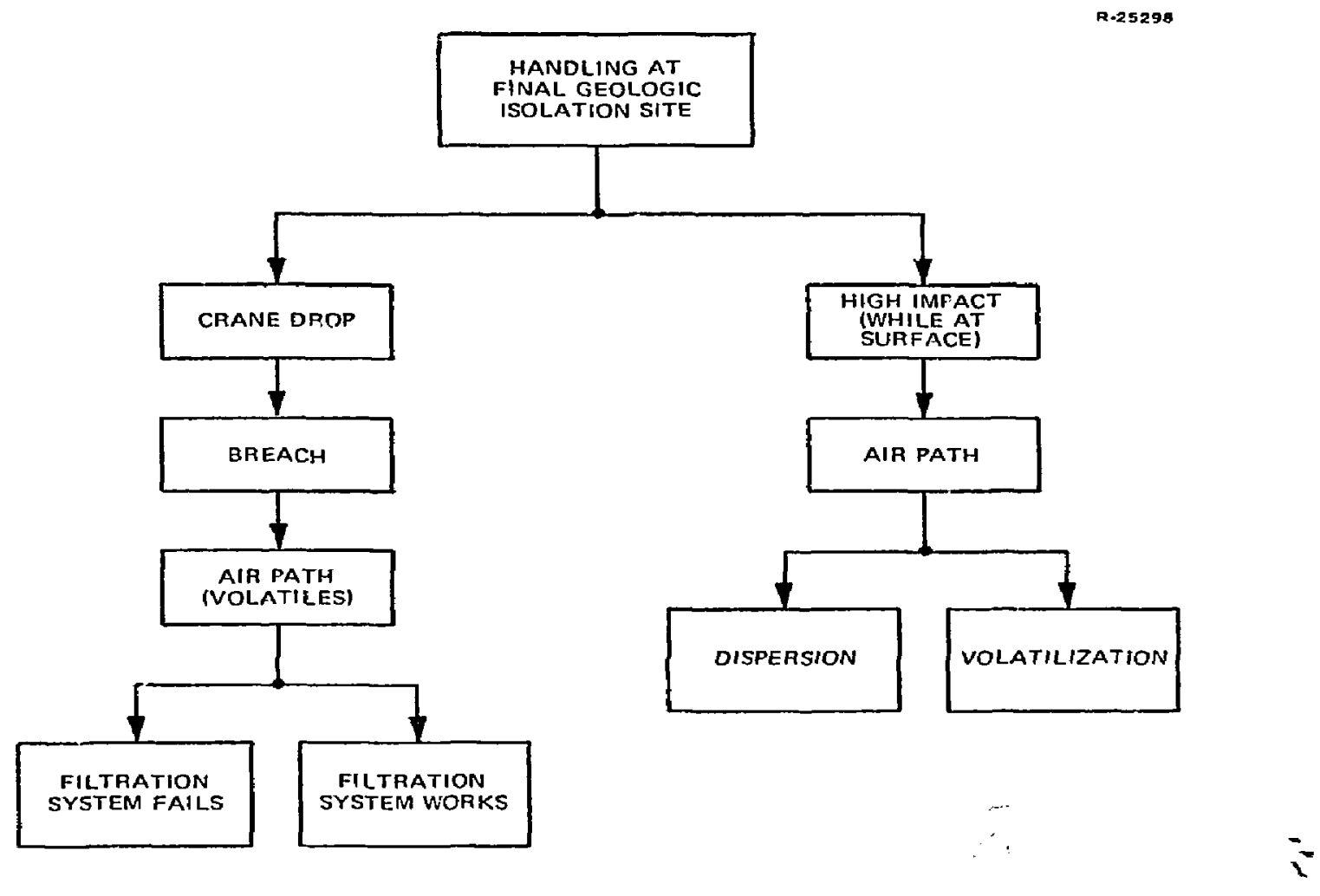

Figure 2.5-1 Event Tree for Handing at the Final Geologic Isolation Site 
assumptions stated above two accident modes are present -crane drop and impact by an aircraft while or the surface.

\subsubsection{Calculation of Release Per Megawatt Electric - Year}

It is instructive to calculate the expected release per Mile-yr for each path in the event tree shown in Fig. 2.5-1. The assumption will be made that the release fractions are unity and that the canister will always breach when it is dropped or impacted. These calculations will show that the expected release for this portion of the waste disposal process is insignificant by comparison with those for other portions.

Crane Drop - Using the crane nominal drop probability of $3 \times 10^{-6} / \mathrm{hr}$ and the nominal handing time of the bare canister of $10 \mathrm{~min}$, the probability of a canister drop per MWe-yr is

$$
\left(3 \times 10^{-6} \frac{\text { accidents }}{\mathrm{hr}}\right) \times\left(\frac{1 \mathrm{hr}}{6 \mathrm{can}}\right) \times\left(\frac{1 \mathrm{can}}{100 \mathrm{MWe}-\mathrm{yr}}\right)=\frac{5 \times 10^{-9} \text { accidents }}{\text { MWe-yr }}
$$

This is the same accident probability as computed for crane stall in Section 2.2. The effect of filter failure or correct operation is the same here, so we can use the result from that section -- e.g., the expected release due to a crane drop accident, given the assumptions stated above, is $10^{-18} 1 / \mathrm{MWe}-\mathrm{yr}$ times the activity contents ( $100 \mathrm{MWe}-\mathrm{yr}$ ) of one canister, or $10^{-16} \mathrm{MWe}-\mathrm{yr}$ waste/MWe-yr. It can be seen that this is very small compared to the expected release computed for interim storage and transportation accidents. 
Impact By an Aircraft - The expected release from an aircraft accident is computed using the accident density of $1.2710^{-10}$ crashes/yr mi ${ }^{2}$ given in section 2.3 and a nominal train transportation cask cross section to aircraft crashes of $100 \mathrm{yd}^{2} / \mathrm{cask}=3.22 \times 10^{-5} \mathrm{mi}^{2} / \mathrm{cask}$ :

$$
\left(1.27 \times 10^{-10} \frac{\text { crashes }}{\text { yr mi }}\right)\left(3.22 \times 10^{-5} \frac{\mathrm{mi}^{2}}{\text { cask }}\right)=4.09 \times 10^{-15} \frac{\text { crashes }}{\text { cask yr }}
$$

Recalling that the cask is nominally on site for 1 week, the expected release for aircraft crash on a train cask is (for release fractions of unity)

$$
\frac{4.09 \times 10^{-15}}{52}=7.09 \times 10^{-17} \frac{\text { MWe-yr waste }}{\text { MWe-yr }}
$$

(The effect of assuming truck transportation can only reduce this figure since the waste is less densely placed in trucks. The possibility of hitting several casks exists but this could only raise the expected release by an order of magnitude, at most.) It can be seen that expected release from this accident is very small compared to that computed for interim storage and transportation accidents. 


\subsection{RELEASE AFTER SEALING THE FINAL GEOLOGIC ISOLATION SITE}

The analysis of release of radionuclides from final geologic isolation sites requires a modeling approach which is considerably different from those discussed in preceding sections, because of the long time-spans of interest. In the model discussed below all material is eventually releaseu, although it may take a very long time, allowing radioactive decay to reduce the ultimate consequences to safe levels. The major pathways considered involve water reaching the burial cavity, leaching out the material and slowly carrying it to surface water. Seismic events are important in initiating the conditions under which such processes would occur. Other pathways involve loss of administrative control and "extraordinary occurrences".

Construction of the event tree used in the current investigation relied heavily on the discussion in Chapter 3 of Battelle document, BNWL-1900 (Ref, 1). This tree was then used as the basis for constructing a "probability flow diagram" which was employed to calculate the relevant "state probabilities". This type of analysis has not, to our knowledge, previously been applied to this problen. The computer program used to generate numerical results can be readily expanded as the event tree grows in complexity.

\subsubsection{Assumptions and Sources of Data}

The assumed final isolation geometry is pictured in Fig. 2.6-1. The burial vault or reposjtory is in a thick layer of material (shale, granite, etc.) which is dry at the time of emplacement. A vertical shaft from the surface to the repository passes through: 


\section{GEJMETRY ASSUMED}

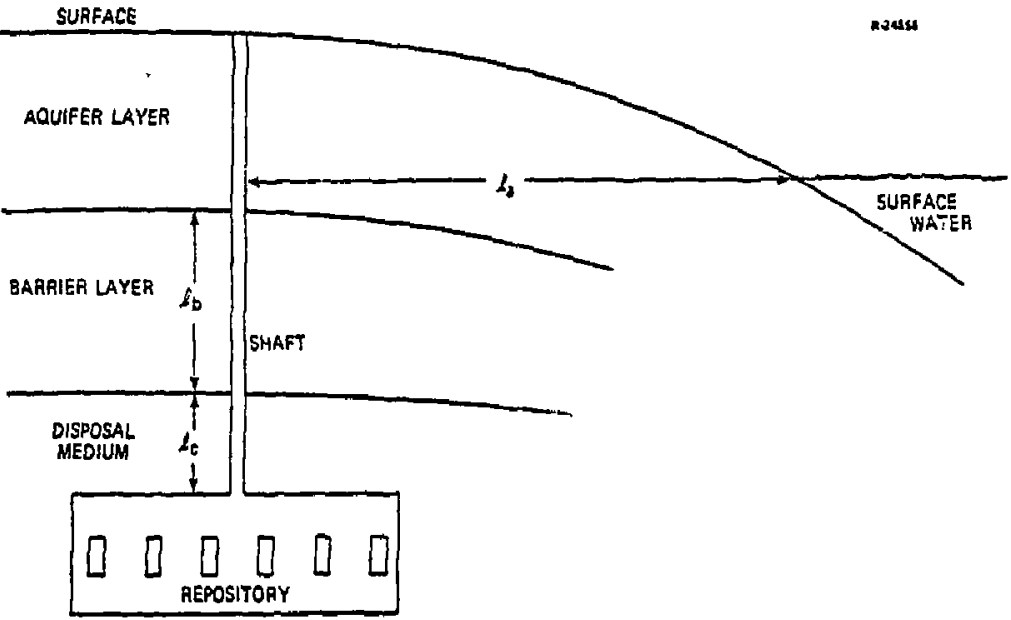

Figure 2.6-1 Final Geologic Isolation Geometry

- An aquifer layer, containing slowly moving groundwater, and

- A barrier layer, thought to be impermeable to water.

At some time after the waste canisters have been placed in the repository, the shaft is sealed so that water cannot enter. Reentry by humans would also be made very expensive and dificult.

In Chapter 3 of Ref. 1 a "fault tree" approach was used to define possible sequences of events leading to release from zeologic isolation. The accompanying discussion of the events and scenarios identified, including judgenents expressed about the relative importance of these scenarios, has guided the current investigation in two ways: first, in 
the development of the event tree given in Section 2.6.2, and second, in the initial choice of some of the controlling probabilities used in generating numerical results.

As mentioned above, a model is constructed in which 211 of the waste material is eventually released by one pathway or another. It is assumed that the region selected is not one of high seismic activity (not near a tectonic plate boundary). However, seismic activity is important in a number of the pathways considered.

Seismic events and their effects have been categorized into smail, medium and large classes. In actuality a continuum of possibiljties exists, but some sort of lumping is necessary to achieve a tractable, finite-state model. Table 2.6-1 summarizes probabilities and "tramsition rates" corresponding to these three types of seismic events and other events discussed in Section 2.6.2. A transition rate, $\lambda_{i}$, is defined in terms of the conditional probability of a transition to a particular state (due to an event "i") during an interval $\Delta t$, given that an appropriate predecessor state exists at the start of the interval. Namely,

$$
\lambda_{i}=\lim _{\Delta t \rightarrow 0} \frac{\text { Prob[event } i \text { during } \Delta t / \text { approp. predecessor }]}{\Delta t}
$$

The $\lambda_{i}$ have units of inverse time. The use of these parameters is discussed further in Section 2.6.3. One column in Table 2.6-1 lists nominal values or "best estimates". The two columns at the right provide low and high or "endpoint" values; these are used in sensitivity calculations designed to illustrate the effect of changed assumptions. 
TABLE 2.6-1

ASSUMED PROBABILITIES AND TRANSITION RATES

FOR FINAL GEOLOGIC ISOLATION, TREE

\begin{tabular}{|c|c|c|c|c|c|}
\hline \multirow{3}{*}{ 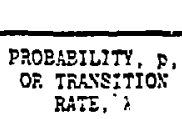 } & \multirow{3}{*}{ EVEST } & \multicolumn{4}{|c|}{ VALTES } \\
\hline & & \multirow{2}{*}{$\begin{array}{l}\text { XOAIXRL } \\
\text { VALIT }\end{array}$} & \multirow{2}{*}{ (0kit5) } & \multicolumn{2}{|c|}{ END POINTS } \\
\hline & & & & 205 & BICA \\
\hline$P_{A}$ & $\begin{array}{l}\text { ORIGINAL FEAT IN SEAL } \\
\text { GR BARRIER }\end{array}$ & $1 \times 10^{-4}$ & $(-)$ & $1 \times 10^{-2}$ & $1 \times 10^{-6}$ \\
\hline${ }^{2} \mathrm{~B}$ & SMALL SEISUIC ACTIVITT & $1 \times 10^{-3}$ & $\mathrm{YP}^{-1}$ & $1 \times 10^{-2}$ & $1 \times 10^{-4}$ \\
\hline$\lambda_{C}$ & WEDILY SEISHIC ACTIVITH & $1 \times 10^{-4}$ & $\mathrm{YR}^{-1}$ & $1 \times 10^{-3}$ & $1 \times 10^{-5}$ \\
\hline$\lambda_{D}$ & LARGE SEISHIC ACTIVITY & $1 \times 10^{-5}$ & $\mathrm{YR}^{-1}$ & $1 \times 10^{-4}$ & $1 \times 10^{-6}$ \\
\hline$\lambda_{E}$ & $\begin{array}{l}\text { CGAYEE IN SURFACE RATER } \\
\text { PPOXIHITH }\end{array}$ & $1 \times 10^{-6}$ & $\mathrm{TH}^{-1}$ & $1 \times 10^{-5}$ & $1 \times 10^{-?}$ \\
\hline 3 & $\begin{array}{l}\text { LOSS CF ADUINISTRATIVE } \\
\text { CONTROL }\end{array}$ & $1 \times 10^{-4}$ & $\mathrm{rR}^{-1}$ & $1 \times 10^{-3}$ & $1 \times 10^{-5}$ \\
\hline${ }^{\lambda} G$ & DRILLIXG OPEYS PATEWAY & $4 \times 10^{-4}$ & $\mathrm{YR}^{-1}$ & $4 \times 10^{-3}$ & $4 \times 10^{-5}$ \\
\hline$\lambda_{E}$ & EKTRAOPDINAFY OCCURRENCES & $1 \times 10^{-9}$ & $Y_{R}^{-1}$ & $1 \times 10^{-7}$ & $1 \times 10^{-11}$ \\
\hline
\end{tabular}

Specific information pertaining to the events, transition rates and data sources is summarized below.

Seismic activity levels are lumped into three categories:

Small: VI on the Modified Mercalli scale (see Ref. 9)

Medium: VII to VIII on the Modified Mercalli scale

Large: IX or above on the Modified Mercalli scale

The different levels result in different effective column lengths, along which nuclides migrate to surface water, and different ground water velocities.

- The transition rates for the three seismic levels ( $\lambda_{B}, \lambda C, \lambda D$ ) are estimated based on data from Table 19-1, Ref. 10 (this data is plotted in Fig. 2,6-2) and the discussion on pages $3.27-3.28$, Ref. 1 . The latter cites as original sources Refs, 11 and 12 . 


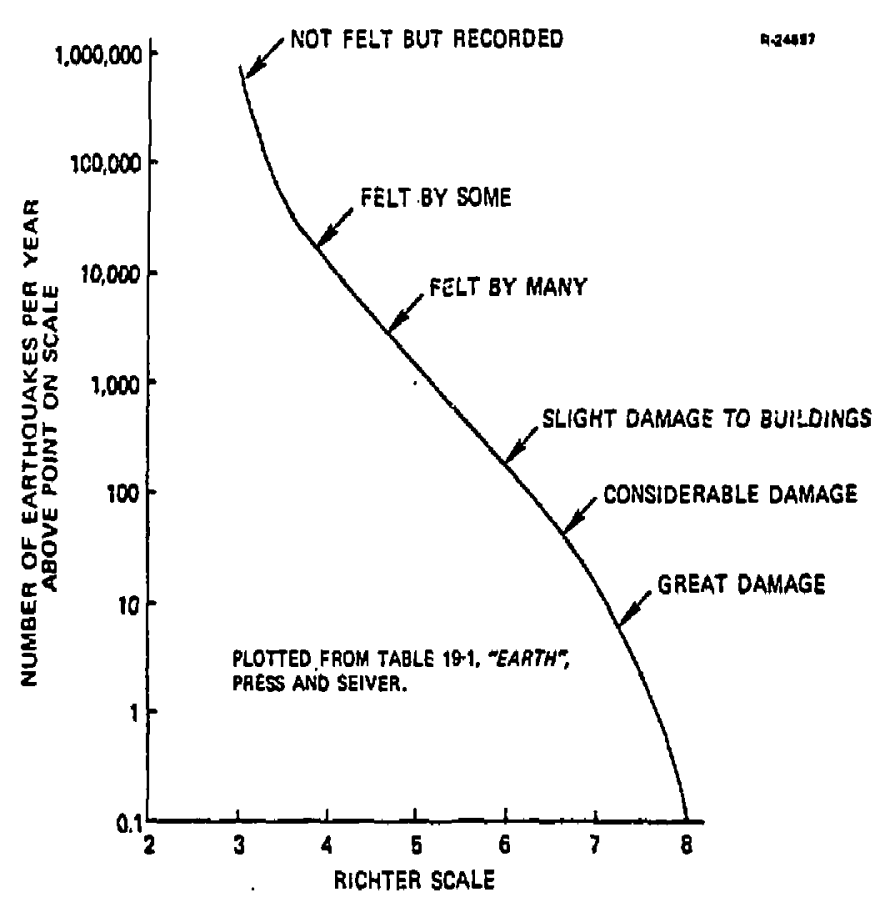

Figure 2.6-2 Earthquake Frequency vs Magnitude

A good discussion of the reiationship between the Modified Mercalli scale (intensity at point of interest) and the Richter scale (magnitude at epicenter) may be found in Ref. 9 .

- Original Flaw in seal or barrier. The probability estimate follows the discussion on pages 3.23 and 3.27 , Ref. 1 ; original sources cited are Refs. 13, 14, and 15 .

- Change in surface water proximity. The transition rate estimate follows the discussion on page 3.27 , Ref. 1; original source cited is Ref. 16. 
Loss of administrative control. The transition rate estimate follows the discussion on the probality of war (page 3.36, Ref. 1) adjusted for likelihood of reinstatement of control.

- Drilling opens pathway. The transition rate estimate follows the discussion on pages 3.33-3.34, Ref. 1; original source cited is Ref. 17.

- Extraordinary occurrences: Page 3.31 of Ref. 1 gives the probability of a volcano as $10^{-4}$ times the probability of large seismic activity; original source cited is Ref. 16. Page 3.31 of Ref. 1 gives the probability of a large meteor removing the barrier as $10^{-14}$ /site-year. Refs. 18 (page $107)$ and 19 contain related information.

The estimate of frequency of occurrence (transition

- rate) of large seismic activity was taken from a discussion, in Ref. 1, related to a "generic Eastern site". This estimate could be modified as follows. First, Ref.12 divides the U.S. into four broad zones. The "strain release index" for the Central Plains zone is approximately one-fifth that of the Eastern zone; the index for the Rocky Mountain zone is approximately twice that of the Eastern zone. (The Pacific West zone index is considerably higher than the other three.) Second, careful selection of a repository site within any of the quieter three zones, such that no known fault lines are nearly, would justify a reduction in the assumed transition rates.

The following events and processes are not included in the initial analysis reported herein: Adversary action, glacial action, erosion of barrier, failures caused by monitoring or testing, migration of cavity, cavity collapse due to radiation, and volcanic or meteor effects -- except minimal considerations under "extraordinary occurrences". All of the above are discussed in Chapter 3 of Ref. 1 and judged to be far less important than the factors which are included in the event tree discussed below. 


\subsubsection{Event Tree}

The event tree representing pathways from final Eeologic isolation is shown in Fig. 2.6-3. The block at the top of the diagram represents the initial condition or "state of the system", corresponding to zero failures or events of consequence. Various event chains or pathways lead to the bottom of the diagram, corresponding to conditions under which nuclides have entered ground water and are migrating toward the biosphere. The diagram is constructea so that, in general, reading from left to right, the pathways become less likely but more disastrous.

Some of the steps (lines connecting blucks) in Fig. 2.6-2 are labeled with probabilities or transition rates: $P_{A}, \lambda_{B}, \lambda_{C}$, etc. These are the parameters which are tabulated in Section 2.6.1 and which control the calculations presented in Section 2.6.3. All of the other events shown are assumed to occur, with probability one, as a direct consequence of the controlling events. For example, given that an original flaw exists in the seal or barrier, then the subsequent events in the left-most path (failure to detect or correct flaw, water flow into cavity begins, canister disintegrates, and leaching and migration begins) are assumed to occur immediately.

\subsubsection{Methodology and Sample Calculations}

The event tree for final geologic isolation pathways, Fig. 2.6-3, does not lend itself directly to the generation of appropriate equations for computing probabilities. For example, an event $C$, initiating release of nuclides into ground water under one set of conditions, can be followed by an event $D$, worsening the conditions and speeding up the transport of nuclides to the biosphere. Thus, a more complex 


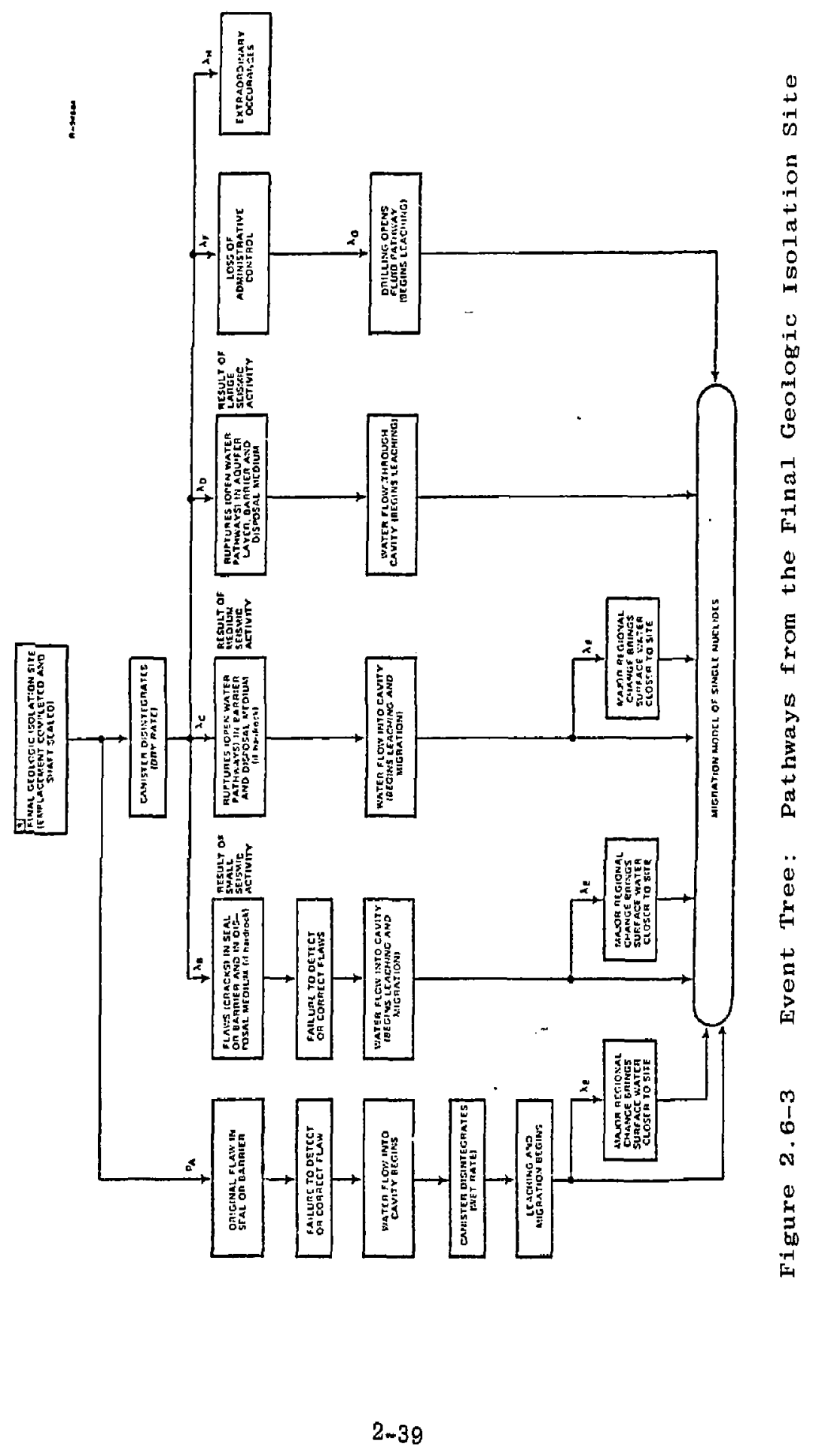


diagram is needed -- one which takes such transitions into account. The new diagram can also be simplified in certain respects -- for example, if tvo parhways lead to equivalent release conditions, they can be joined in a composite or merged "node." Note also, that simplifications based on small-number assumptions (ala WASH-1400) cannot be used here because of the very long times involved. That is, after sufficient rime has elapsed some of the node probabilities will become large. Therefore, computer solutions which take proper account of all couplings, via transitions between nodes, are necessary.

Figure 2.6-4 is a "probability flow" diagram illustrating the transitions between nodes discussed above. Nodes can be categorized as follows:

- Single-Event Nodes, such as

$C$ - Event $C$ has occurred ${ }^{*}$

$E$ - Event $E$ has occurred

$Z$ - (Special case) Zero events have occurred

- Joint-Event Nodes, such as

$C E$ - Events $C$ and $E$ have occurred

$E F$ - Events $E$ and $F$ have occurred

- Merged Nodes, such as

$A / B$ - Either $A$ or $B$ or both have occurred

$D / G$ - Either $D$ or $G$ or both have occurred

- Compound Nodes, such as
$(A / B) E$ - Either $A$ or $B$ or both, and $E$ have occurred
(A/B)EF - Either A or B or both, and $E$ and $F$ have occurred

\footnotetext{
*A more precise definition is: Event $C$ has occurred, but no other events leading to worse (or potentially worse) release conditions have occurred. Thus, A or $B$ may have occurred, but $D, E, F, G$ or $H$ have not.
} 


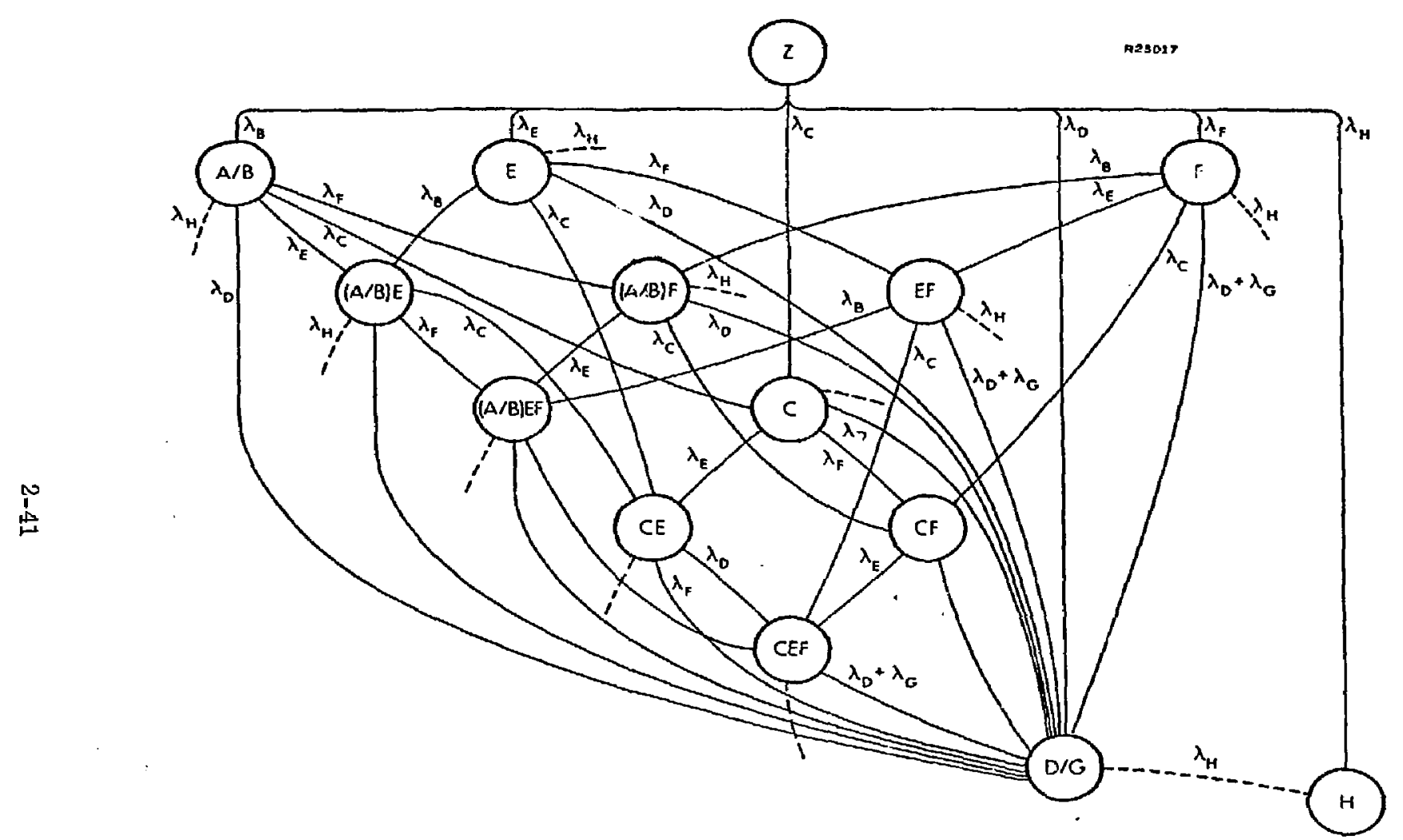

Figure 2.6-4

Probability Flow Diagram Corresponding to Final Geologic Isolation Event Tree 
A set of simultaneous ordinary linear differential equations, describing how "probability flows" through the model, can be written down by inspection of the diagram of Fig. 2.6-4. These equations are readily solved using an appropriate computer program.

Th 14 nodes or states of the diagram in Fig. 2.6-4 can be groupec according to subsets which have equivalent release conditions. The groups are:

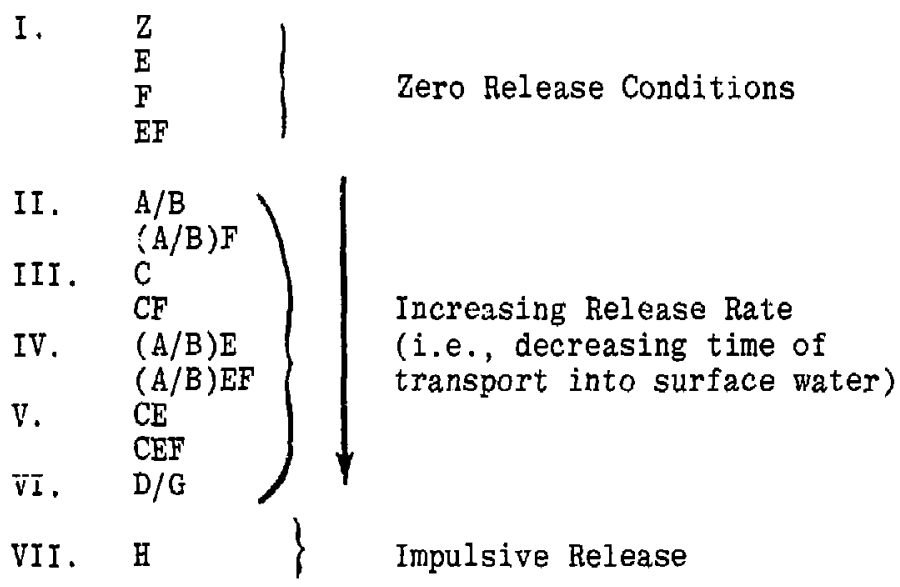

The "state variables" to be calculated are the elements of a 14-state probability vector, $p(t)$. Each element, $p_{i}(t)$, represents the probability of being in a particular state $i$ at tire $t$. The vector state-dynamic system equation to be solved is

$$
\dot{p}(t)=M p(t)
$$

where $M$ is a $14 \times 1.1$-dimensional matrix of transition rates. For example, defining state 1 as the $z$-state (zero events) and state 2 as the $A / B-s t a t e$, then 


$$
\begin{aligned}
& M_{1,1}=-\lambda_{B}-\lambda_{C}-\lambda_{D}-\lambda_{E}-\lambda_{F}-\lambda_{H} \\
& M_{2,1}=+\lambda_{B} \\
& M_{2,2}=-\lambda_{C}-\lambda_{D}-\lambda_{E}-\lambda_{F}-\lambda_{H}
\end{aligned}
$$

The computer solutions are found using the "transition matrix" $\phi(t)$ defined in terms of the matrix exponential function.

$$
\phi(t)=e^{M t}
$$

The solution at any time $t$ is determined by the initial condition, $\underline{p}(0)$, and is given by

$$
\underline{p}(t)=\phi(t) \underline{p}(0)
$$

In this case the initial condition is:

$$
\begin{aligned}
& p_{1}(0)=1-p_{A} \\
& p_{2}(0)=p_{A} \begin{array}{l}
\text { (probability of original flaw in } \\
\text { seal or barrier) }
\end{array} \\
& p_{3}(0) \rightarrow p_{14}(0)=0
\end{aligned}
$$

Baseline Results - The 14-state system of equations outlined above was solved out to one million years, using the baseline case parameters shown in Table 2.6-1. The fourteen probabilities were grouped as listed above and the group sums are plotted versus time in Fig. 2.6-5. It is important to note that the results plotted are very dependent on the assumptions used in these sample calculations. Groups IV, $V$, and VII are not shown because their probabilities are negligible. (As time is extended toward a billion years Group VII will ultimately show up.) Those plotted correspond to the following release scenarios: 


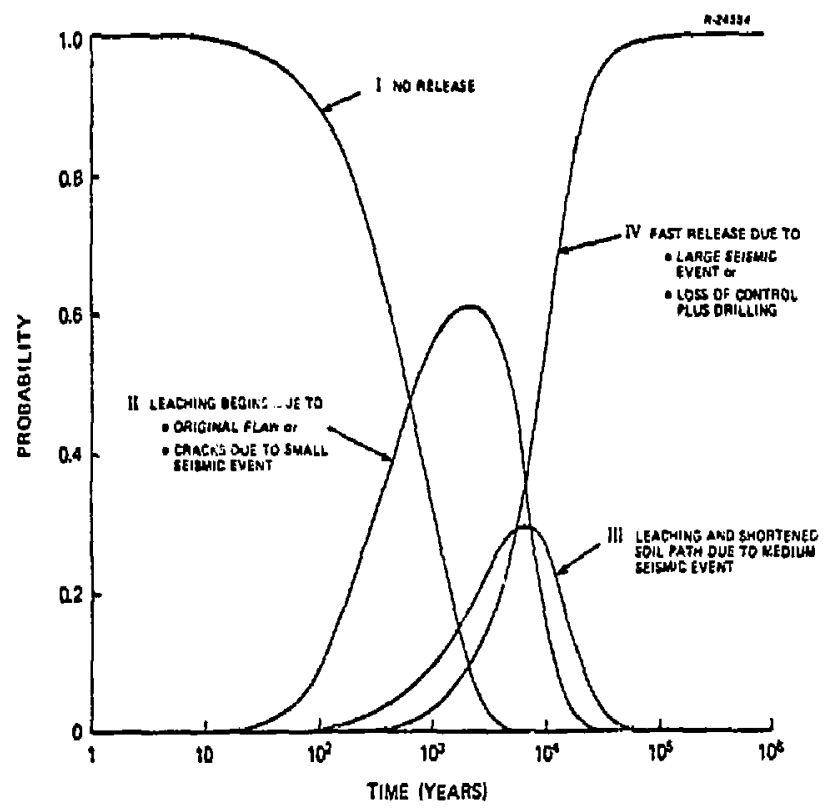

Figure 2.6-5 Group Probabilities vs Time: Baseline Case

Group I. No release

Group II, Leaching begins due to either an original flaw in the seal or barrier, or cracks caused by a small seismic event. (The latter dominate.)

Group III. Leaching begins (or continues, if a Group II event predated the Group III event) and the effective soil column is shortened due to a medium-sized seismic event.

Group IV. Leaching begins (or continues, if a Group II or III event predated the Group VI event) directly into the surface water due to a large seismic event or due to the combination of loss of administrative control plus drilling by man. (The latter is more important in this case.) 
: Jnre 2.6-5 shows the progression of probabilities of the above groups as a function of time after emplacement. Notice that the probability of Group I (no release) decreases monotonically with time, as would be expected -- the longer the material has been in the ground the higher the probability of some release. As time progresses in Fig. 2.6-5 the situations which imply intermediate release rates (Groups II and III) increase and then decrease in probability, as each is supplanted by the rising probability of a more serious set of circumstances. After a certain time the probability that Group VI (faster release) has been experienced dominates.

Examination of the baseline case curves in Fig. 2.6-5 leads to the following observations:

- Release of nuclides is dominated ty the events leading to the states in Groups II and VI.

- After 2000 years the probability is 0.6 that the state of the system lies in Group II and leaching wiIl have begun.

- After 30,000 years the probability is near unity that the state of the system lies in Group VI. That is, either a large seismic event or the combination of loss of control plus drilling will have opened up a direct pathway to surface water.

Thus, a typical case might be: entry into Group II at 500 years, followed by entry into Group VI at 10,000 years. At the latter time the amount of nuclides remaining in the soil column, if any, depends on the leach rate, the groumd water velocity, the column length, etc. Meaningiul statistical calculations based on a model for leaching and migration requires a joint probability density function for the two variables: 


$$
\begin{aligned}
& \tau_{I I} \text { - Time of entry into Group II } \\
& { }^{\tau_{V I}}-\text { Time of entry into Group VI }
\end{aligned}
$$

Those cases where the Group II event follows the Group VI event have no importance. In order to provide a relatively simple-to-work-with initial set of numerical data, a discrete joint density function was generated using approximate graphical techniques based on the computer data from this baseline case. The function is tabulated in Table 2.6-2; the twelve entries in the table serve as weighting functions for twelve ri.igration model scenarios -- see Section 3.2.

TABLE 2.6-2

DISCRETE JOINT DENSITY FUNCTION FOR INITIATING EVENT TIMES: BASELINE CASE

\begin{tabular}{|c|c|c|c|c|}
\hline${ }^{\top}$ II & $\begin{array}{c}5000 \\
\text { yrs }\end{array}$ & $\begin{array}{c}10,000 \\
\text { yrs }\end{array}$ & $\begin{array}{c}20,000 \\
\text { yrs }\end{array}$ & $\begin{array}{c}\text { No } \\
\text { EVENT }\end{array}$ \\
\hline \hline $200 \mathrm{yrs}$ & 0.23 & 0.13 & 0.06 & 0.05 \\
$600 \mathrm{yrs}$ & 0.16 & 0.09 & 0.04 & 0.03 \\
$1000 \mathrm{yrs}$ & 0.10 & 0.06 & 0.03 & 0.02 \\
\hline
\end{tabular}

Example Variations - A set of ten additional conputer calculations were generated to show the effects of variations in the input parameters from their baseline values. The resulting probabilities for Groups I, II, III and VI were plotted for three cases -- Case 4: High Seismic Activity; Case 5: Low Seismic Activity; Case 9: Better Administrative Control -- in Figs. 2.6-6, 2.6-7, and 2.6-8, respectively.

Comparison of Case 4 (Fig. 2.6-6) with the baseline case shows a similar pattern of group probability histories, 


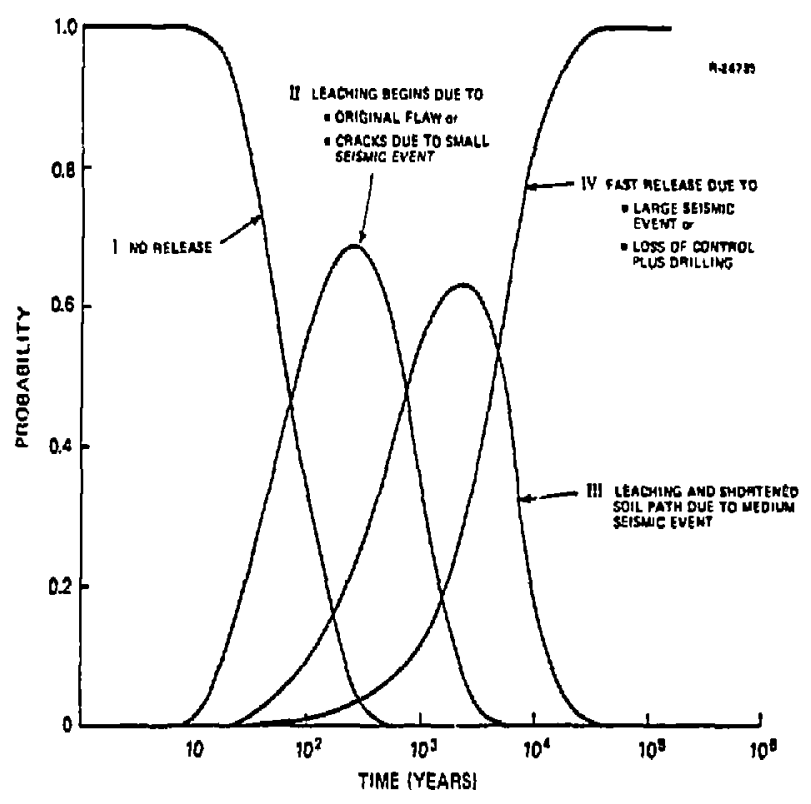

Figure 2.6-6 Group Probabilities vs Time: High Seismic Activity

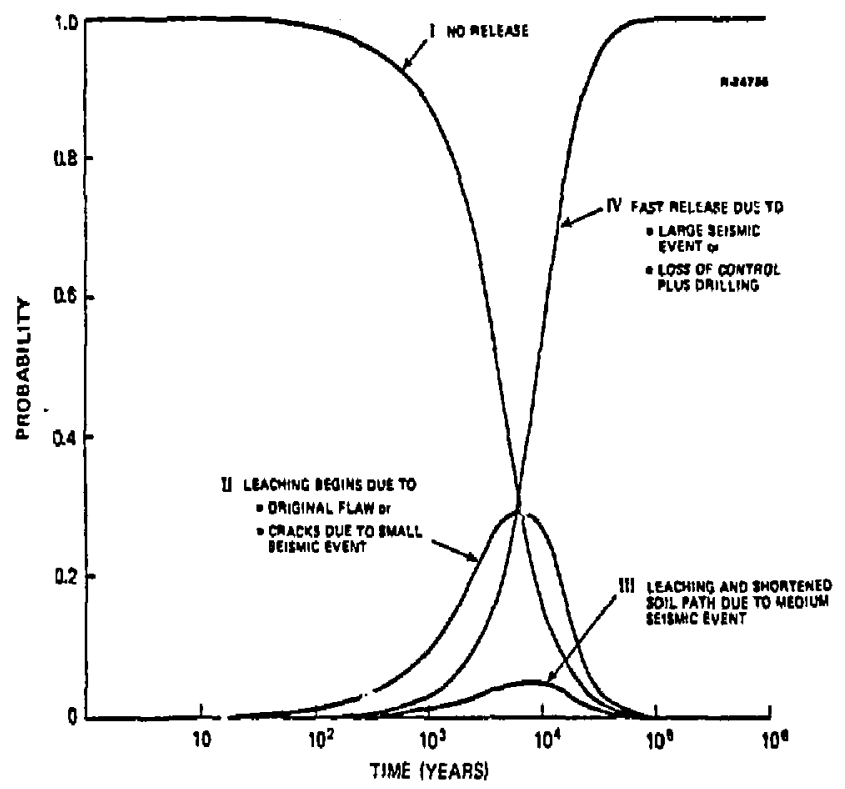

Figure 2.6-7 Group Probabilities vs Time: Low Seismic Activity 


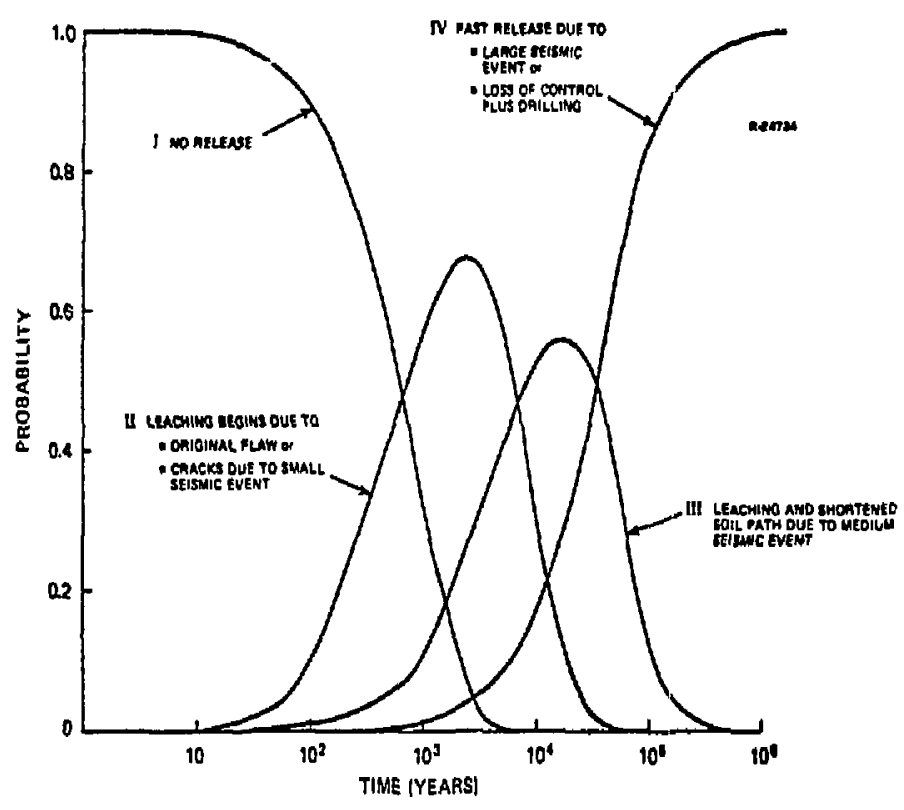

Figure 2.6-8 Group Probabilities vs Time: Better Administrative Control

but with events occurring (statistically) earlier in time. Also, Group III plays a more significant role -- it is not so closely overridden by Group VI because Group VI events are no longer dominated by the "F-G" path (loss of control plus drilling) as in the baseline case. Rather, it is dominated by the "D" path (large seismic events) whicl are less likely than the "C" path (medium seismic events) of Group III.

Case 5 (Fig. 2.6-7) releases are dominated by Group VI alone. Here, the seismic activity paths ( $B, C$ and $D)$ have been so reduced in likelihood that the non-seismic part of Group VI -- the "F-G" path (loss of control plus drilling) is practically all that matters.

Case 9 (Fig, 2,6-8) shows a similar pattern to that of Case 4 (Fig. 2.6-5), but with everything happening later 
in time. As in Case 4 the three types of seismic events dominate, but here it is done by making the "F-G" path less probable, rather than by making the " $\mathrm{B}$ ", " $\mathrm{C}$ " and " $\mathrm{D}$ " paths more probable. The Groups I and II probability histories are very similar to those of the baseline case.

As stated earlier, the results illustrated by these sample calculations are very dependent on the assumed probabilities and event tree structure. The mechodology illustrated can be readily extended to a more complex event tree (or trees) corresponding to a more elaborate description of final geologic isolation pathways.

\subsection{CHAPTER SUMMARY}

This chapter has described the functional event tree and its individual components. A number of calculations have been presented to show how various paths on the event tree were eliminated from further cousideration on the basis of the relative expected release per megawatt electric-year. Transportation and water storage a the fuel reprocessing plant have been identified as the major sources of accidentally release radionuclides prior to emplacement. 


\section{MATHEMATICAL MODEL FOR PROPAGATION AFTER RELEASE}

\subsection{WATER RELEASE FROM REPOSITORY}

\subsubsection{General Characteristics}

The water release model of Ref. 20 was taken as a point of departure for constructing a model for flow of radionuclides from the repusitory to the biosphere. This model assumes that radionuclides begin leaching out of the repository starting at 100 years after emplacement and then flow through an aquifer of constant cross-sectional area. To make this model more ralistic, the following modifications were made:

- Start of leaching was assumed to begin at the time of the first earthquake or breach of the repository. This corresponds to the time of first transition from Group I in the markov chain model of Section 2.6.

- The rate of leaching of waste from the original solid form was assumed to decrease rather than remaining constant. This reflects the decrease in the surface area of the solid as it is dissolved. For simplicity, an exponential decline was assumed.

- The volume of the repository and shaft was accounted for.

- Transverse dispersion of the waste as it flows through the aquifer was modeled by assuming a soil column with increasing cross-sectional area. 
- The velocity of water flow through the aquifer was assumed to be $0.1 \mathrm{ft} / \mathrm{day}$ rather than $1.0 \mathrm{ft} / \mathrm{day}$.

- Buildup of radionuclides in topsoil, sediment, and the human population was explicitly modeled.

All of these modifications tend to make the model less conservative than the model used in Ref. 20 .

For ease of computation, lumped-parameter models were used to approximate the partial differential equations for nuclide flow. No appreciable loss of fidelity is expected. A detailed explanation of the models fo: lows.

\subsubsection{Lumped-Parameter Models, Nuclide Concentration}

The flow of a nuclide through a water system can be modeled by dividing the system into cells and writing differential equations for the concentration of the nuclide in each cell. For constant-volume cells, the rate of change of conceitration in each cell is given by

$$
\frac{d C}{d t}=\frac{1}{V} \frac{d m}{d t}
$$

where $m$ is the mass of material in a particular cell and $V$ is the cell's volume.

The first step in developing the models is writing a mass balance for each cell. Atomic decay and birth account for part of the change in nuclide mass within a cell. However, for the moment only forces causing flow into and out of a cell will be considered. 
There are two forces driving the flow of nuclides into or out of a cell: the bulk movement of the water and diffusion. The mass flow out of a cell carried along with the water flow is given by

$$
\phi_{\mathrm{f}}=\frac{\mathrm{C}}{\mathrm{K}} F
$$

where

$\mathrm{C}$ is the concentration $\left(\mathrm{Ci} / \mathrm{m}^{3}\right)$ of the nuclide in the cell the water is leaving.

$F$ is the water flow rate $\left(\mathrm{m}^{3} / \mathrm{yr}\right)$

$K$ is the "retention factor" which measures the slowing down of nuclide movement due to ion exchange, precipitation, and other sorption phenomena. ( $\mathrm{K}-1$ is the fraction of the nuclide mass in the cell that is free to move with the water.) $\mathrm{K}$ may vary with $C$, but experimental measurements of this dependence are very scarce. In these calculations we will take $K$ to be constant. $K$ can be computed from

$$
K=1+\frac{\rho_{b}}{n} K_{d}
$$

where $\rho_{b}$ is the bulk density of the porous medium, $\mathrm{n}$ is the porosity, and $\mathrm{K}_{d}$ is the ratio of the concentrations of the free and sorbed phases of the species involved.

This mass flux can also be expressed as

$$
\Phi_{f}=\frac{C}{\bar{K}} \vee A
$$

where

$\nu$ is the average water velocity $(\mathrm{m} / \mathrm{yr})$ 
and

\section{$A$ is the cross-sectional area of the cell, assumed to be normal to the direction of flow.}

Mixing processes such as thermal diffusion, disturbance of flow patterns by the medium, etc. will cause spatial variations in concentration to be smoothed. This will result in a flow of nuclides from regions of high concentration to regions of low concentration. The mass flow from cell $A$ to cell $B$ resulting from all mixing processes may be represented by a diffusion-type equation:

$$
\Phi_{D}=\frac{D\left(C_{A}-C_{B}\right)}{K \Delta} A
$$

where

$$
\begin{aligned}
& D \text { is a coefficient giving the strength } \\
& \text { of mixing processes }\left(\mathrm{m}^{2} / \mathrm{yr}\right) \\
& \mathrm{C}_{\mathrm{A}} \text { is the concentration }\left(\mathrm{Ci} / \mathrm{m}^{3}\right) \text { ir cell } \mathrm{A} \\
& \mathrm{C}_{\mathrm{B}} \text { is the concentration }\left(\mathrm{Ci} / \mathrm{m}^{3}\right) \text { in cell } \mathrm{B}
\end{aligned}
$$

and

\section{$\Delta$ is the distance between the centers of cells $A$ and $B$}

When thermal diffusion is the dominant mode of mixing, the dispersion coefficient $D$ will be equal to the diffusion constant of the ion divided by a factor which will be greater than unity and will depend only on the geometry of the pores in the medium. When other mixing processes are present, they will increase $D$ above this value. If the medium is anisotropic the value of $D$ may depend on direction. In general, $D$ will differ from the diffusion constant as usually defined in physical chemistry. 
It is reassuring to note that, by taking the limit as the cell volume goes to zero, the three-dimensional diffusion equation

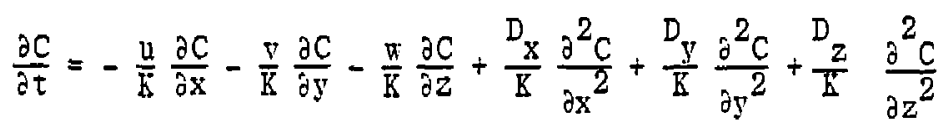

is derived. Here $u, v$, and $w$ are water velocities in the $x, y$, and $z$ direction and $D_{x}, D_{y}$, and $D_{z}$ are the dispersion coefficients in the $x, y$, and $z$ directions.

By making the cell size sufficiently small, any desired fidelity of the model to the real world can be obtained. Of course, as the size of the cells is decreased, the amount of computation required to exercise the model increases because the more cells must be added.

\subsubsection{Leaching of Solid Waste Forms}

A reasonable model for leaching of a solid waste form is the first order differential equation

$$
\dot{m}_{c_{j}}=-\lambda_{\ell} m_{c_{j}}
$$

where $\lambda_{\ell}$ is the leach rate and $m_{C_{j}}$ is the mass of species $j$ remaining in the original waste deposit. In practice, the leach rate will depend on the surface area of the waste deposit as well as the volume. In the interest of simplicity, that dependence, as well as any protective effect of the waste containers, has been neglected. 


\subsubsection{Migration from Repository to Surface Water}

The general form of the model for miglation of nuclides through the ground is shown in Fig. 3.1-1.

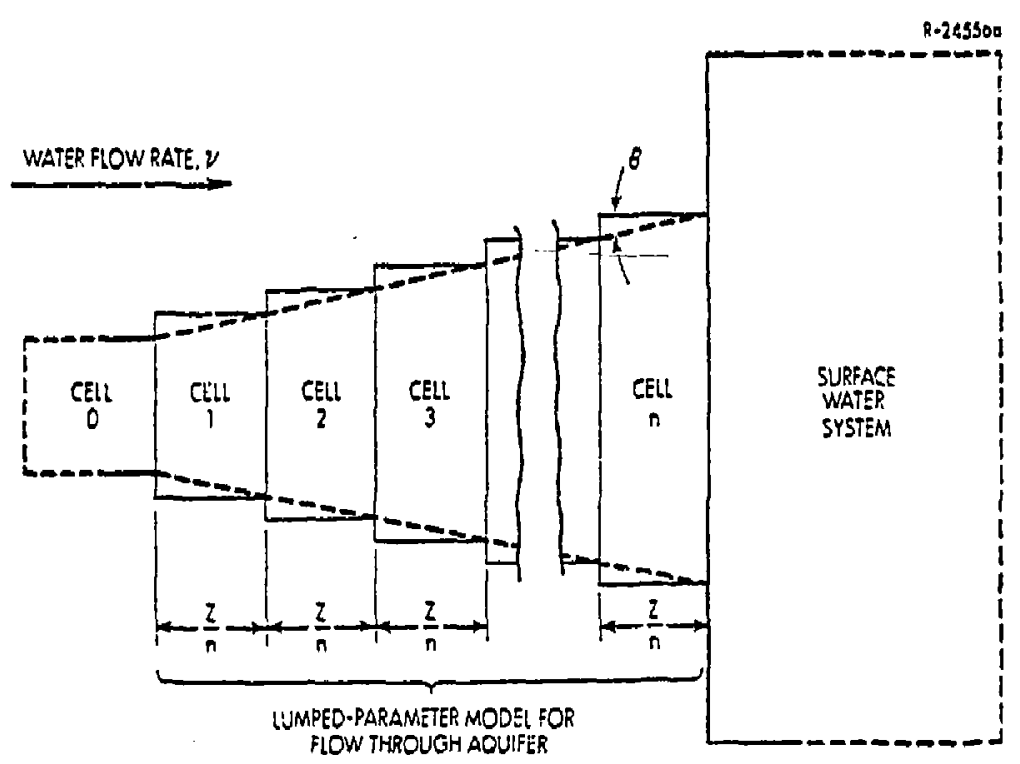

Figure 3,1-1 Ground Water Migration' Model

Cell 0 is the repository and shaft. The model assumes that nuclides which leach from the solid waste are uniformly mixed through the repository and shaft in a fairly short time. The mass balance for cell 0 is shown in Fig. 3.1-2. $\left(\lambda_{j}\right.$ is the atomic decay rate of nuclide $j$, equal to in 2 divided by the balf-life.)

As the nuclide moves away from the repository, mixing processes cause it to be distributed through a broader cross-section. Rather than trying to explicitly model the lateral spread of the nuclide, we have assumed that it is present in a cone whose apex is cell 0 . The 


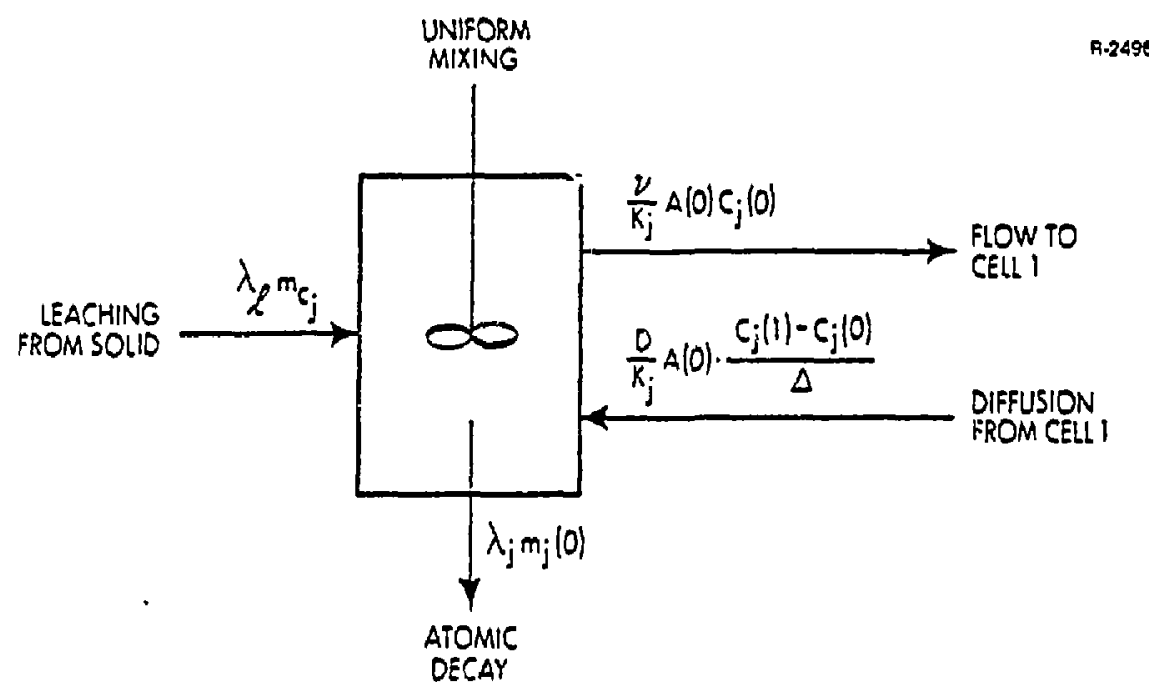

Figure 3.1-2 Mass Balance for Repository and Shaft

cells are slices of the cone with their sides set parallel to the flow axis in order to simplify the calculation. Within each cell the concentration is taken to be uniform. Although this assumption suppresses any explicit modeling of mixing in the lateral and vertical directions, the mixing term for flow from cell to cell along the iongitudinal direction is still included in our model.

For the sake of simplicity, the cross-sectional area of the nuclide distribution has been taken to increase linearly with distance from the source. The model could aasily be modified to incorporate cross-sections derived directly from the diffusion equation.

The mass balance for cells 1 through $\mathrm{n}-1$ is shown in Fig. 3.1-3. Here $\Delta z$ is the distance between cells. The mass balance for the last cell in the aquifer is slightly different; it is shown in Fig. 3.1-4. This cell discharges into some surface water body. Since the surface water is mixed much 


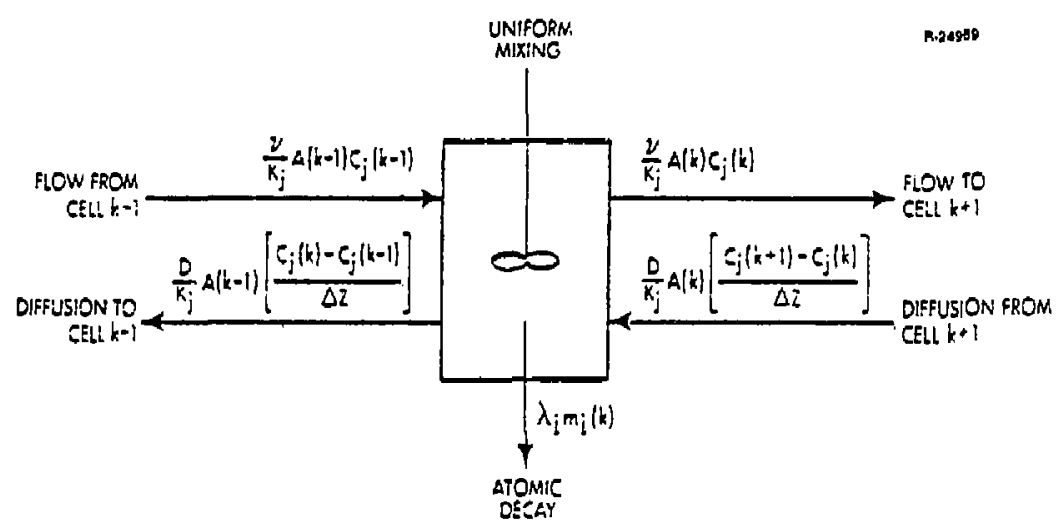

Figure 3.1-3 Mass Balance in Typical Aquifer Cell

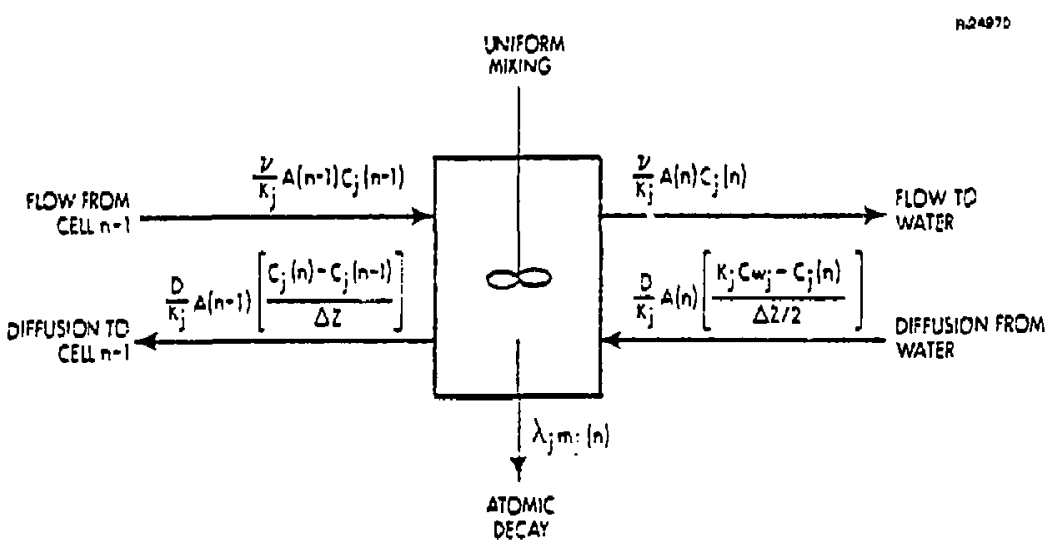

Figure 3.1-4 Mass Balarce for Last Aquifer Cell

faster than the aquifer, the distance for mixing out of the cell is halved.

The mass balances of Figs. 3.1-2 through 3.1-4 correspond to first-order ordinary differential equations for the concentration in each cell. These equations are listed in Appendix A. 


\subsubsection{Migration through Surface Water}

Figure 3.1-5 diagrams the model for the surface-

3. water system. In this system nuclides may be stored in the water, sediment, topsoil and in the human population. The mass balance for the water is shown in Fig. 3,1-6. Figure 3.1-7 and 3.1-8 show the mass balance for the topsoil and the people. Figure 3.1-9 shows the mass balance for the sediment, subsoil, etc.

These mass balances correspond to first-order ordinary differential equations for nuclide concentrations in each component of the system. Appendix B lists these equations.

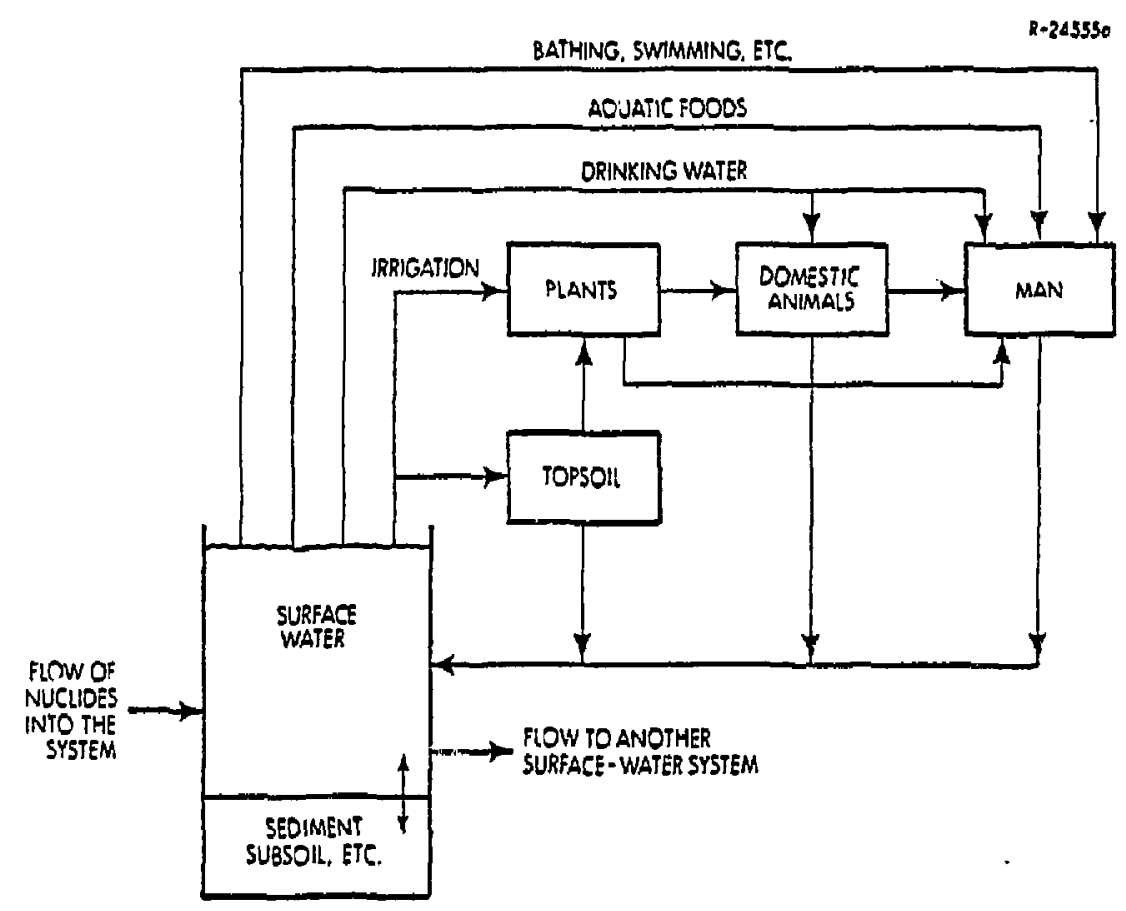

Figure 3.1-5 Model for Surface-Water System 


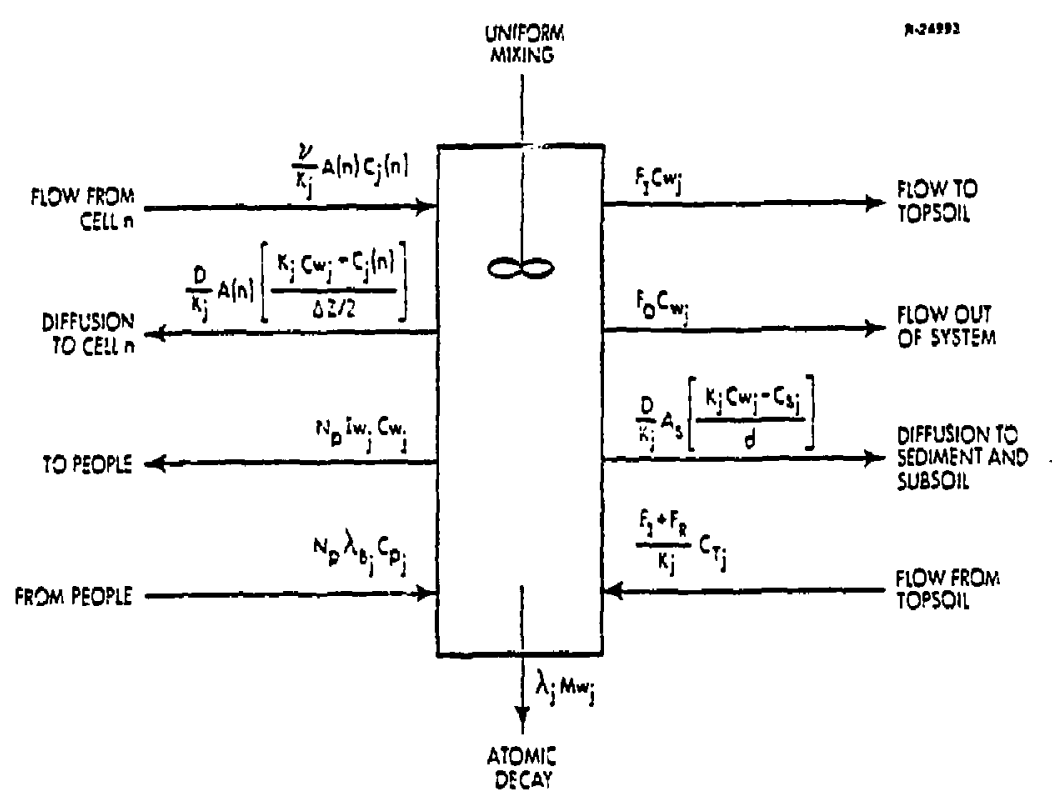

Figure 3.1-6 Mass Balance for Water

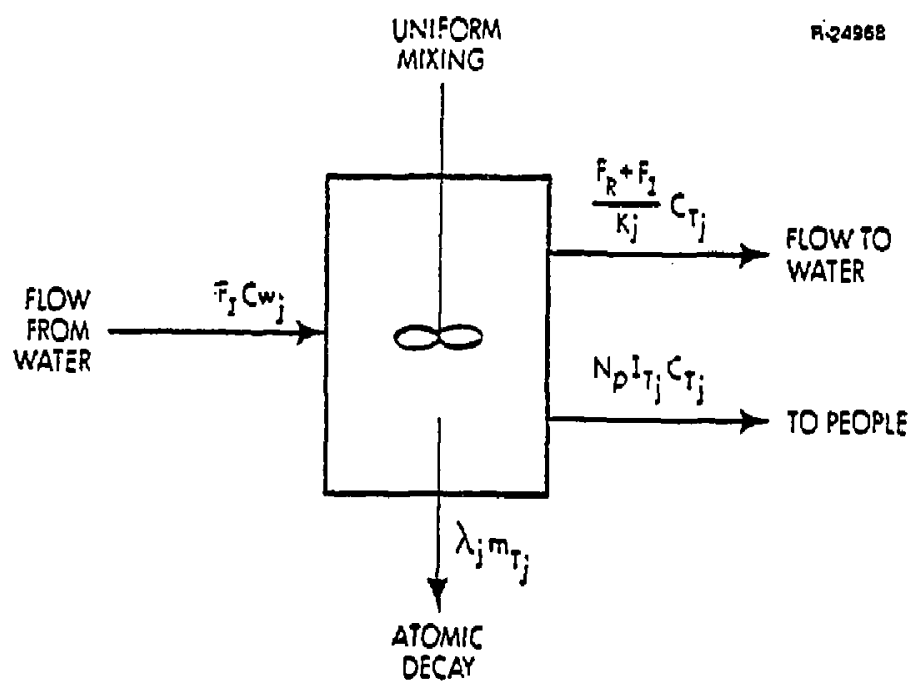

Figure 3.1-7 Mass Balance for Topsoil 


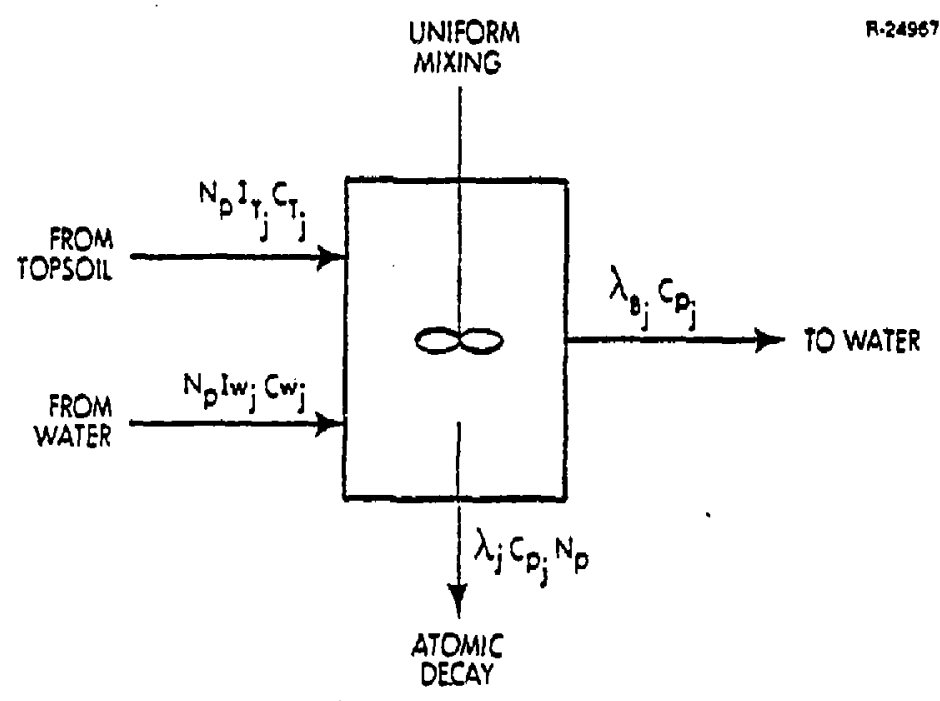

Figure 3.1-8 Mass Balance for People

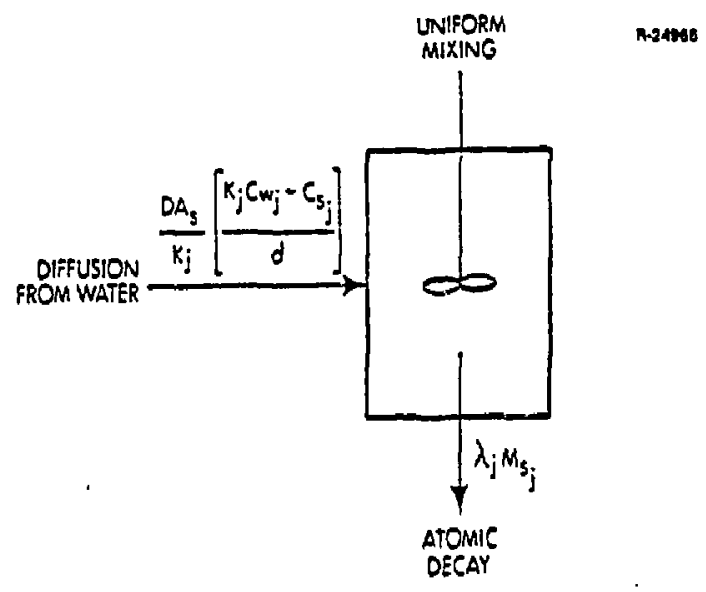

Figure 3.1-9 Mass Balance for Sediment, Subsoil, etc. 
The notation used in Figs. 3,1-6 through $3,1-9$ is as follows:

$$
\begin{aligned}
& A_{s}=\text { the area of the sediment and subsoil }\left(\mathrm{m}^{2}\right) \\
& d=\text { the average diffusion depth of the } \\
& \text { sediment and subsoil (m) } \\
& F_{I}=\begin{array}{l}
\text { the irrigation flow rate }\left(\mathrm{m}^{3} / \mathrm{gr}\right) \text { from the } \\
\text { water system }
\end{array} \\
& F_{0}=\begin{array}{c}
\text { the flow rate }\left(\mathrm{m}^{3} / \mathrm{yr}\right) \text { of water out of the } \\
\text { system }
\end{array} \\
& \mathbb{N}_{P}=\text { the number of people using the water } \\
& \text { system } \\
& \begin{aligned}
I_{w j}= & \text { the effective water intake rate }\left(\mathrm{m}^{3} / \mathrm{yr}\right) \\
& \text { for each individual in the system }
\end{aligned} \\
& F_{R}=\text { the rainfall flow rate }\left(\mathrm{m}^{3} / \mathrm{yr}\right) \\
& \mathrm{C}_{\mathrm{T}}=\text { the concentration in the topsoil }\left(\mathrm{Ci} / \mathrm{m}^{3}\right) \\
& C_{S_{j}}=\text { the concentration in subsoil and sediment } \\
& \mathrm{C}_{\mathrm{p}_{j}}=\text { the concentration in the people ( } \mathrm{Ci} / \text { person) } \\
& \mathrm{I}_{\mathrm{T}_{j}}=\text { the effective topsoil intake rate }\left(\mathrm{m}^{3} / \mathrm{yr}\right) \\
& \lambda_{\mathrm{B}_{j}}=\text { the biological wash-out coefficient }\left(\mathrm{yr}^{-1}\right) \\
& =\frac{0.693}{\text { biological half life }}+\frac{1}{\text { average life span }}
\end{aligned}
$$

\subsubsection{Dose Calculations for Water Release}

The dose calculations used in Ref. 20 were modified to be compatible with explicit modeling of radionuclide buildup in the topsoil. The equations used are presented below. 
Nuclides released in a water system and deposited in the topsoil find their way to the human population through the food chain and through external radiation. The yearly radiation dose for each organ is the sum of the dose from the internally accumulated store of the nuclide and the dose from the dissolved nuclide which passes through the body with ingested water:

$$
\begin{aligned}
\operatorname{dose}(i)= & \sum_{j} D I(i, j) I A(i, j) \\
& +\sum_{j} D E(i, j) C w_{j} .
\end{aligned}
$$

where

$$
\begin{aligned}
& \text { dose }(i)=\text { the total yearly dose to organ } i \\
& \text { (Rem/yr) } \\
& D I(i, j)=\text { the dose conversion factor } \\
& \text { ( }(\mathrm{Rem} / \mathrm{hr}) / \mathrm{Ci}) \text { for ingestion of } \\
& \text { nuclide } j \text {. } \\
& I A(j)=\text { The internal accumulation of } \\
& \text { nuclide } \mathrm{j} \text { ( } \mathrm{C} i \text { ). } \\
& \mathrm{DE}(\mathbf{j}, \mathbf{j})=\text { the dose conversion factor } \\
& \left((\text { Rem } / \mathrm{hr}) /\left(\mathrm{Ci} / \mathrm{m}^{3}\right)\right) \text { for external } \\
& \text { exposure. } \\
& \mathrm{Cw}_{j}=\text { concentration in water }\left(\mathrm{Ci} / \mathrm{m}^{3}\right) \\
& \text { ET = exposure time }(\mathrm{hr} / \mathrm{yr}) \text {. }
\end{aligned}
$$

The internal accumulation is computed by solving the differential equation giving the balance between intake and loss. Losses are computed using a coefficient which lumpts together radioactive decay and departure of the nuclide from the organism. This coefficient is called the biological half-life. 


$$
\frac{d}{d t} I A(i, j)=-\frac{0.693}{\operatorname{BHL}(i, j)} \operatorname{IA}(i, j)+R I(j)
$$

where

$$
\begin{aligned}
\operatorname{BHL}(i, j)= & \text { biological halflife }(y r) \text { of nuclide } \\
& j \text { in organ } i \\
\operatorname{RI}(j)= & \text { intake rate }(\mathrm{C} i / y r) \text { of nuclide } j .
\end{aligned}
$$

The intake rate is the sum of the intakes coming through the food chain from the water and the topsoil:

$$
R I(j)=1000 \operatorname{IW}(j) C_{(j)}+I T(j) C_{T(j)}
$$

where

$$
\begin{aligned}
I W(j)= & \begin{array}{l}
\text { effective intake rate from water } \\
(l / \mathrm{yr})
\end{array} \\
\operatorname{IT}(j)= & \begin{array}{l}
\text { effective intake rate from topsoil } \\
\left(\mathrm{m}^{2} / \mathrm{yr}\right)
\end{array} \\
C_{T}(j)= & \text { concentration in topsoil }\left(\mathrm{Ci} / \mathrm{m}^{3}\right)
\end{aligned}
$$

The effective intake rates from water and topsoil are expressed in the model as the sums of the intakes from various types of food. The routes modeled are fish, other seafood, various vegetables and animal products, and drinking water. For each type of food, there is a concentration factor relating the nuclide concentration in the food to the nuclide concentration in the water. In the case of vegetables and animal products, these concentration factors may be expressed in terms of irrigation and feeding rates. Transfer coefficients will then relate nuclide concentrations in topsoil and drinking and irrigation water to concentrations in food. The equations describing these relationships are listed in Appendix $C$. 


\subsubsection{Parameter Values Assumed}

In studying the release of waste from the repository, the parameter values shown in Table 3.1-1 were assumed and dose calculation parameters were taken from Ref. 20. The factors $\mathrm{k}_{j}^{-1}$, which correspond to the proportion of nuclide $j$ that is mobile in water, were also taken from Ref. 20; however, these factors were modified because full decay chains were not modeled at this time. For iodine and technetium $\mathrm{K}_{j}^{-1}$ was unchanged at 1.0 , but for all other nuclides $k_{j}^{-1}$ was set to 0.01 . This simplification will be removed when full decay chains are modeled because it tends to make the model conservative.

\subsection{WATER RELEASE FOR TRANSPORTATION ACCIDENTS}

The surface-water-system model of Sec. 3.1.5 and the dose calculations of Sec. 3.1.6 were used to assess the effects of a water release resulting from a transportation accident. Because the dose received by an individual is Inearly related to the quantity of each radionuclide released, the dose from $1 \mathrm{Ci}$ released in the water system was calculated for each nuclide, and the results were multiplied by the amount of each nuclide expected to be released.

The parameter values 1 isted in Sec. 3.1.7 were used with the following exceptions:

- $F_{0}$ was changed to $10^{8} \mathrm{~m}^{3} / \mathrm{yr}$ corresponding to a river rather than a lake.

- $\mathbf{K}_{j}^{-1}$ from Ref. 20 were used without modification. 
TABLE 3.1-1

PARAMETERS VALUES ASSUMED

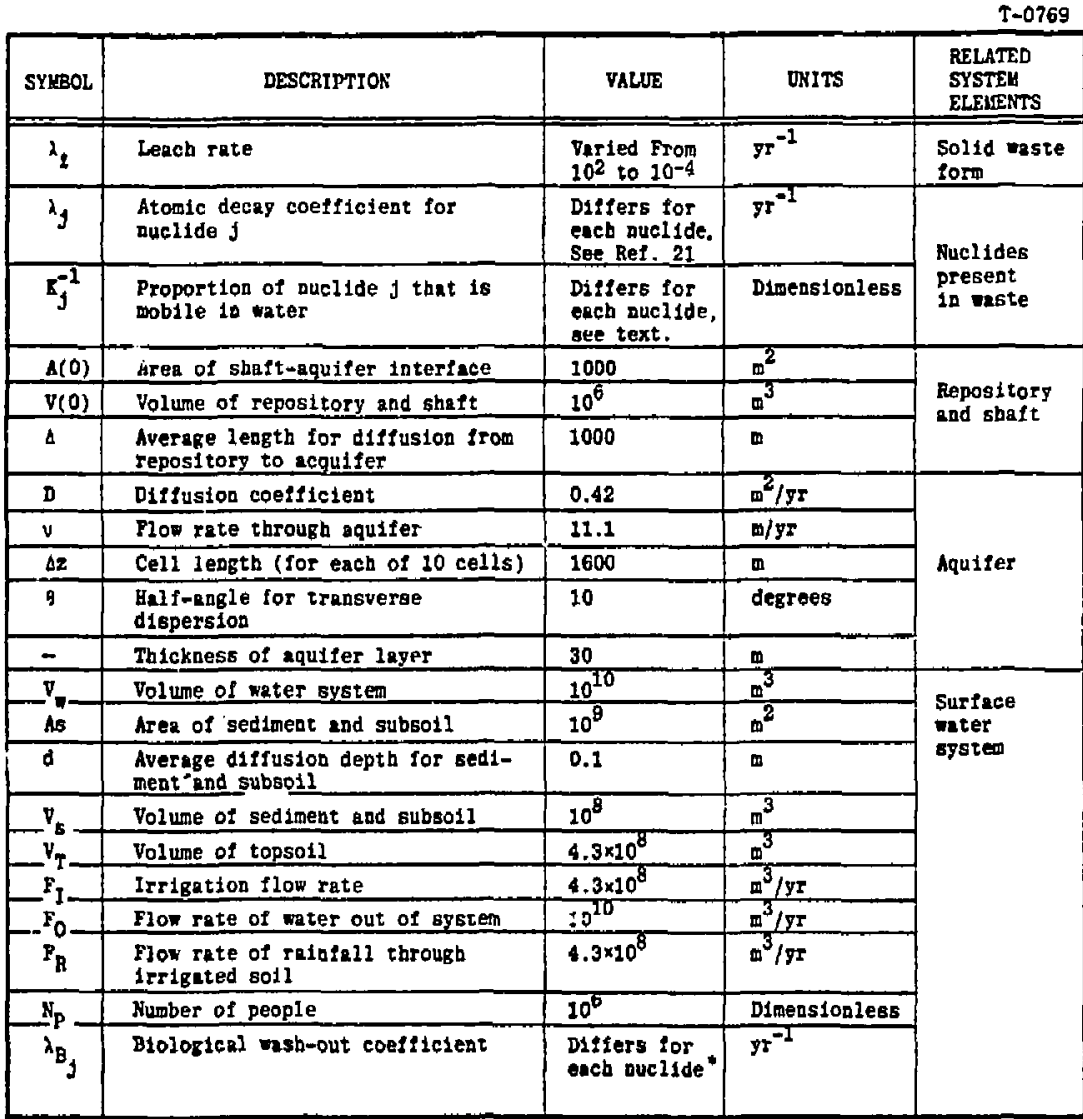

D. Hiller, battalle Pacifle Nortbwest Laboratorles, personal comunication

\subsection{AIR RELEASE}

The model used for propagation of racionuclides released into the air was that described in Ref. 22, Dose conversion factors used to convert concentrations of nuclides into dose to man were provided by LLL. 


\subsection{CHAPTER SUMMARY}

This chapter describes the mathematical model used to represent the flow of radionuclides from a waste repository, through an aquifer and into a surface body of water. It also discusses the model which was used to analyze the various mechanisms by which the nuclides provide a dose to a person living near the surface water body. 
4.

$$
\frac{\text { SENSITIVITY OF POPULATION DOSE TO }}{\frac{\text { CHARACTERISTICS OF HIGH LEVEL }}{\text { SOLIDIFIED WASTE }}}
$$

The mathematical models of release mechanisms and pathways for propagation into man, described in Chapters 2 and 3 , were exercised to determine the sensitivity of population dose to key characteristics of the solid waste form. Specifically, solubility, dispersibility and volatility were considered. The effect of release is computed as the expected value of the 30-year dose to the general population, per megawatt electric year of generation. Where air pathways are concerned the appropriate assumed population distribution is incorporated into the calculation. Where water pathways are concerned the value computed is the expected value of the 30-year individual dose per Mite-yr to a person living near the effected body of water; it is left to the reader to assume a specific population.

The analysis divides naturally into two major categories -- release prior to sealing the repository, "preemplacement", and release after the waste repository is sealed, "post-emplacement." The former involves a large number of possible release modes and pathways and waste that has lost little of its radioactivity since removal from the reactor. The latter centers on dissolving of the solidified waste in the repository, its entry into ground water and, eventually, into surface water and man. The two categories are discussed separately in the sections which follow. 


\subsection{SENSITIVITY ANALYSIS FOR THE PRE-EMPLACEMENT PERIOD}

Identification of Critical Accidents - The number of potential accident modes which can result in the release of radioactive nuclides from HLSW prior to enplacement is large. It will be recalled that for the storage, handling and transportation operations considered in this study two major accident types -- drainage of the interim storage pool a: the FRP and transportation to the repository -- were determined to dominate, in terms of expected population dose per Me-yr, all pre-emplacement accident modes. For that reason sensitivity analyses were completed for these modes only.

Drainage of the Interim Storage Pool - The scenario analyzed was that described in Section 2.3 , where a massive earthquake luptures the storage pool and the building enclosing it and so disrupts services that the canisters of HLSW cannot be cooled. Under these circumstances the waste will. heat up and a certain portion of the canisters will breach, releasing volatiles and exposing materials to dispersion into the air.

Figure 4.1-1 shows the expected value of population dose per year of storage as a function of the fraction of material released in the accident described above. The release fraction is related to the solid waste form and can be used to specify acceptable solid waste characteristics. The lines for 1-yr old waste assume a probability of one that the canisters will breach. Those representing 10-yr old waste are adjusted to account for a probability of 0.1 that the canisters will breach.

From Fig. $4.1-1$, if $10^{-2}$ to $10^{0} \mathrm{Man}-\mathrm{REN} / \mathrm{MWe}-\mathrm{yr}$ is considered to bound the range of largest acceptable population 


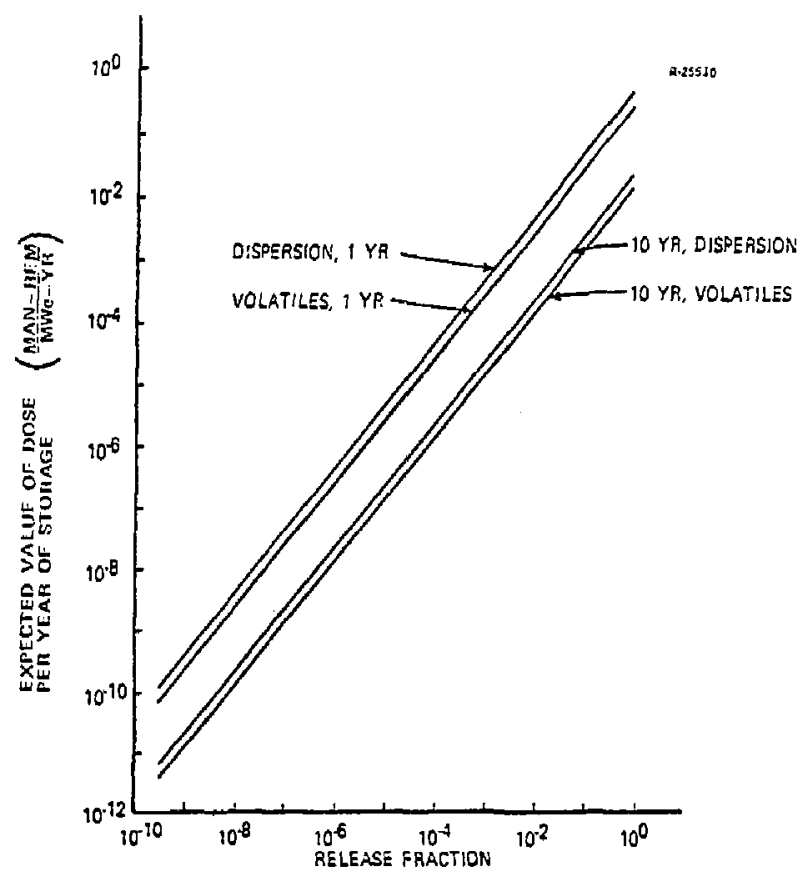

Figure 4.1-1 Expected Dose as a Function of Release Fraction for Drainage of $t$ t 2 Interim Storage Pool

dose, then the range of maximum acceptable release fractions will be $10^{-2}$ to $10^{\circ}$ for $1-\mathrm{yr}$ old waste and $10^{\circ}$ for $10-\mathrm{yr}$ old waste, if the waste is stored for only one $y$ ar. It must be noted that the doses in all pre-emplacem ant accident modes must be added; here $10^{-1}$ Man-REM/MWe-yr for -olatiles is added to the corresponding dose for dispersion, etc. Best engineering judgement suggests that the release fraction for volatiles will be about $10^{-1}$ for both Baseline $A$ and $B$. For dispersion the release fraction for Baseline $A$ may be close to the maximum acceptable level, while for Baseline $B$ it is orders of magnitude lower.

Critical Mode Transportation Accidents - In order to relate the expected population dose in transportation 
accidents to a single parameter -- a characteristic of the HLSW - - a modal accident was defined for each form of transportation accidents. This was done by combining the probability density function (pdf) and the release function for each accident mode. (Both are described in Section 2.4). F'igure 4.1-2 illustrates how the modal accident is defined, using conceptual probability density function and release function curves. The product of the pdf and the release function is formed. In every case it is zero at low accident severities, since no release occurs, and at very high accident severities, since the probability of such severities is zero. At some intermediate point the product reaches a peak value. The modal accident is defined as one with a severity (mph for impact, deg F-min for fire, $\sec ^{-1}$ for punature) equal to that at which the peak value of the product oceurs. The expect value of population dose is computed as a function of the release fraction -- the fraction of available radioactivity that escapes from the protective system under conditions determined by the modal accident. In general, there are different modal accidents for each accident mode - impact, fire, puncture -- for each solid characteristic -dissolution, dispersion, volatization -- and for each transportation mode studied -- truck and train. Table 4.1-1 provides a statement of the modal accident conditions (the fire modal severity, def F-min, is broken down into separate components of time and temperature in Table 4.1-1).

\section{Senitivity Relations for Transportation Accidents -}

Figures 4.1-3 through 4.1-6 illustrate the sensitivity of the expected value of population dose to the release fraction for those transportation accidents which involve air pathways to the biosphere. The plots are easily compared with the sensitivity relations for loss of water in the interim storage pool shown in Fig. 4,1-1. It can be seen that the difference 

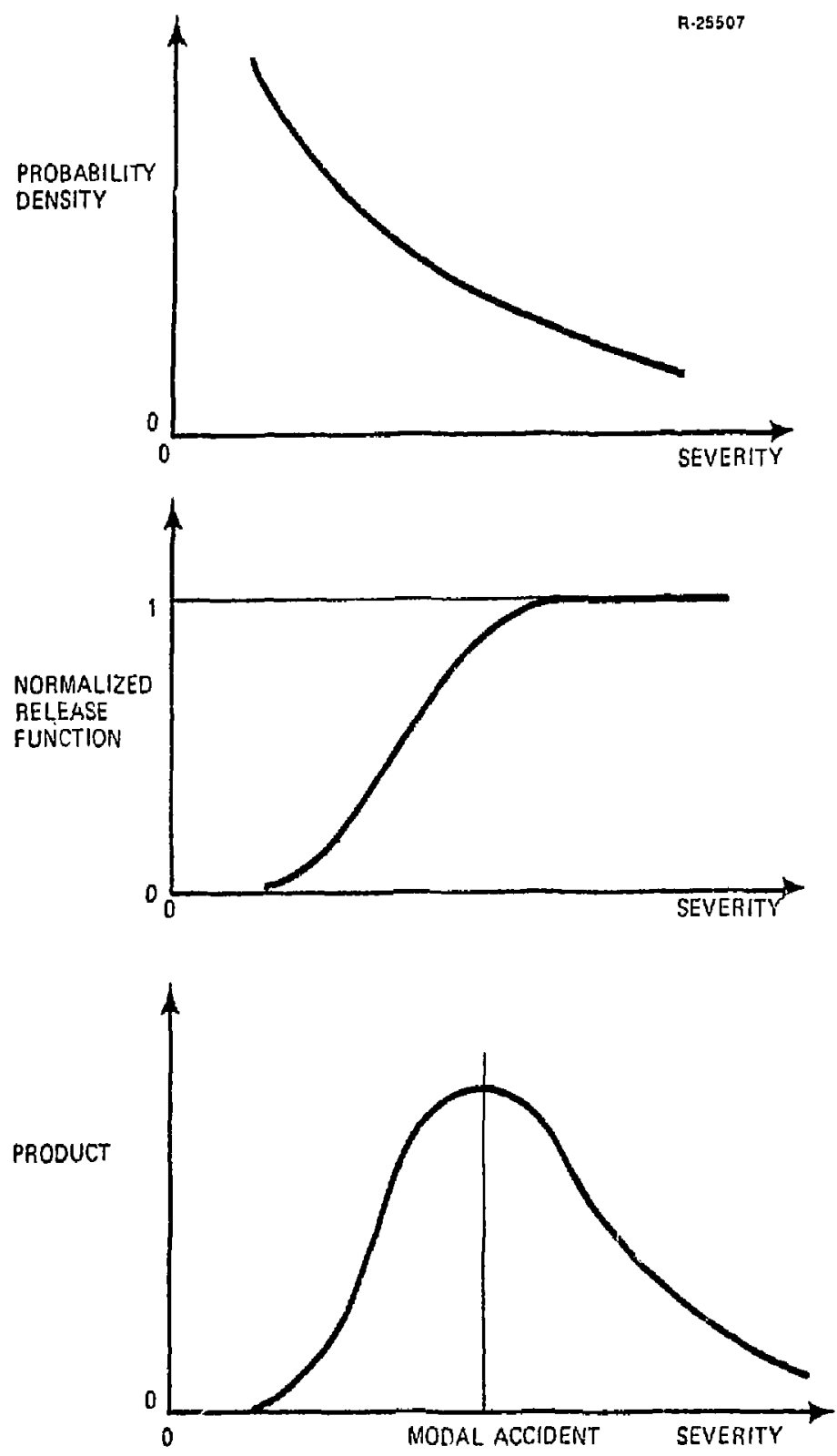

Figure 4.1-2 Definition of Modal Accident 
TABLE $4.1-1$

MODAL ACCIDENT CONDITIONS

\begin{tabular}{|c|c|c|}
\hline & TRUCK & TRAIN \\
\hline $\begin{array}{l}\text { Impact-Dispersibility } \\
\text { impact valocity (mph) }\end{array}$ & 60 & 50 \\
\hline $\begin{array}{l}\text { Puncture-Dispersibility } \\
\text { impact velocity (mph) }\end{array}$ & 40 & 40 \\
\hline $\begin{array}{c}\text { Fire Dispersibility } \\
\text { temperature (oF) } \\
\text { time (minutes) }\end{array}$ & $\begin{array}{r}2000 \\
80\end{array}$ & $\begin{array}{r}2000 \\
45\end{array}$ \\
\hline $\begin{array}{c}\text { Fire-Volatilit } \ddot{y} \\
\text { temperature }\left({ }^{\circ} \mathrm{F}\right) \\
\text { time (minutes) }\end{array}$ & $\begin{array}{r}2000 \\
80\end{array}$ & $\begin{array}{r}2000 \\
240\end{array}$ \\
\hline $\begin{array}{l}\text { Impact-Dissolution } \\
\text { impact velocity }(\mathrm{mph})\end{array}$ & 60 & 50 \\
\hline $\begin{array}{l}\text { Puncture-Dissolution } \\
\text { impact velocity (mph) }\end{array}$ & 40 & 40 \\
\hline $\begin{array}{l}\text { Fire-Dissolution } \\
\text { temperature (or) } \\
\text { time (minutes) }\end{array}$ & $\begin{array}{r}2000 \\
80\end{array}$ & $\begin{array}{r}2000 \\
240\end{array}$ \\
\hline
\end{tabular}

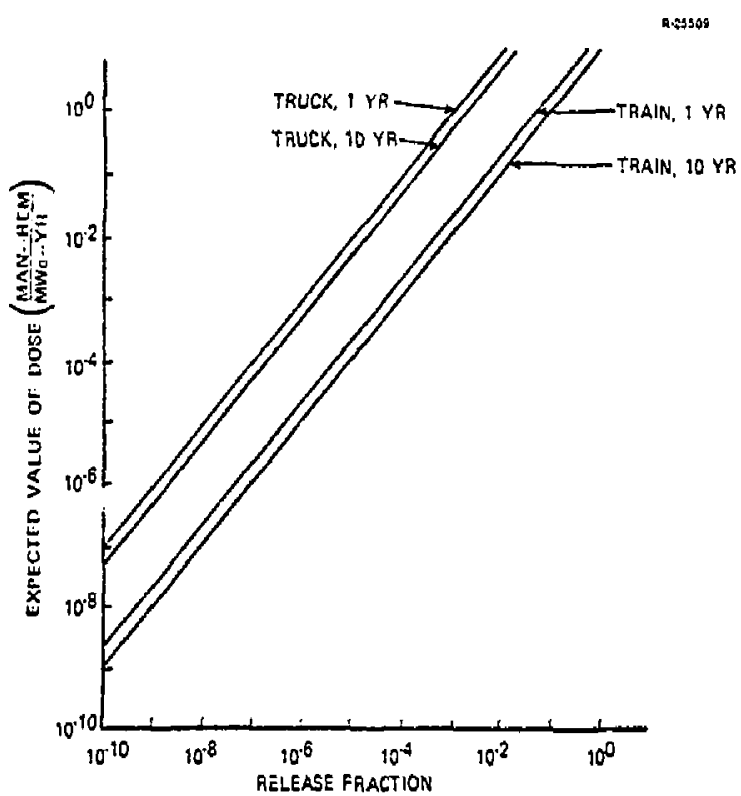

Figure 4.1-3 Sensitivity of Dose to Solid Characteristics: Transportation, Dispersion, Impact 


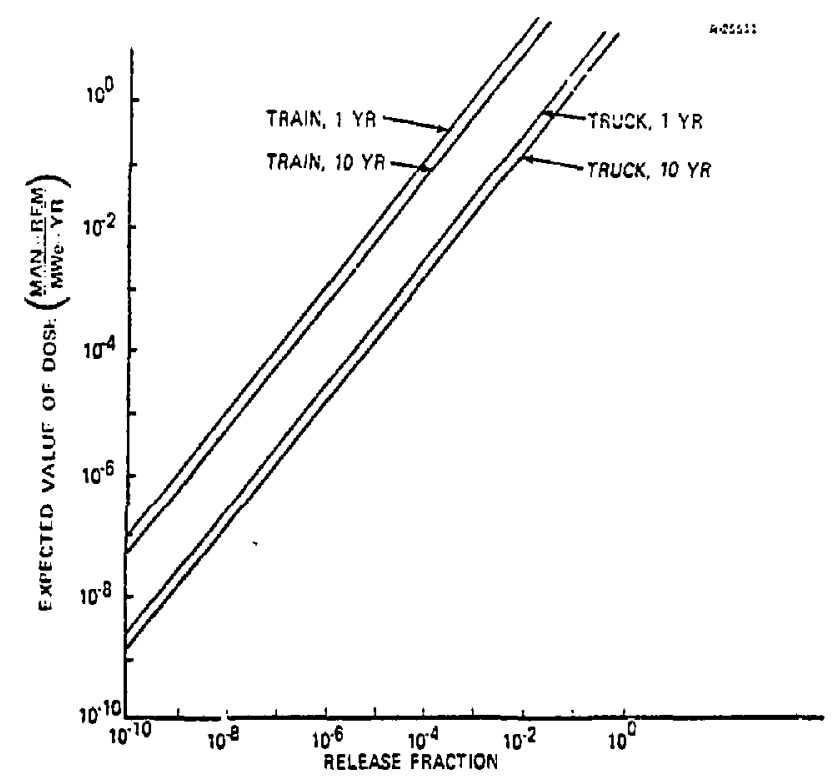

Figure 4.1-4 Sensitivity of Dose to Solid Characteristics: Transportation, Dispersion, Fire

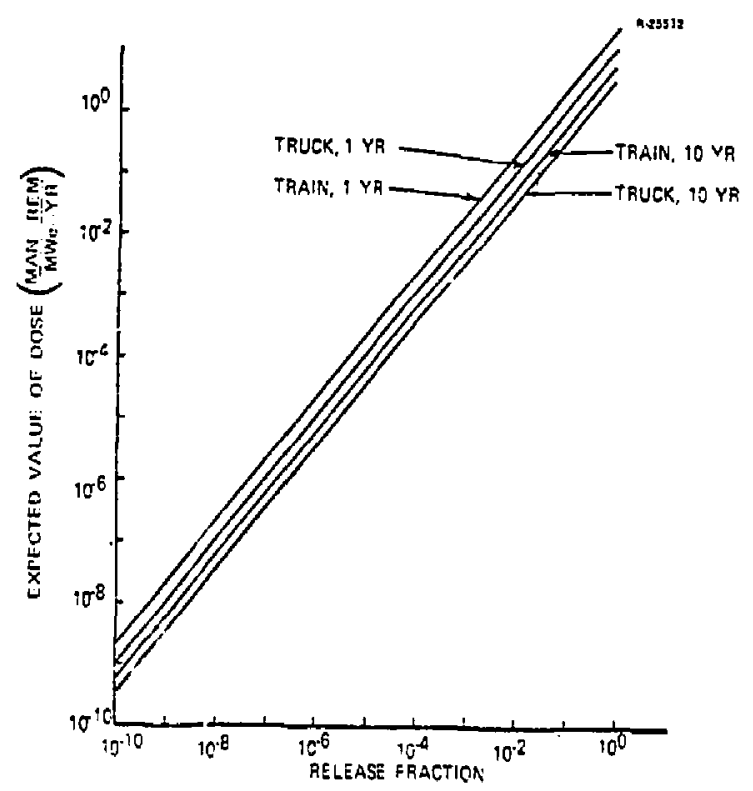

Figure 4.1-5 Sensitivity of Dose to Solid Characteristics: Transportation, Volatiles, Fire 
i

1

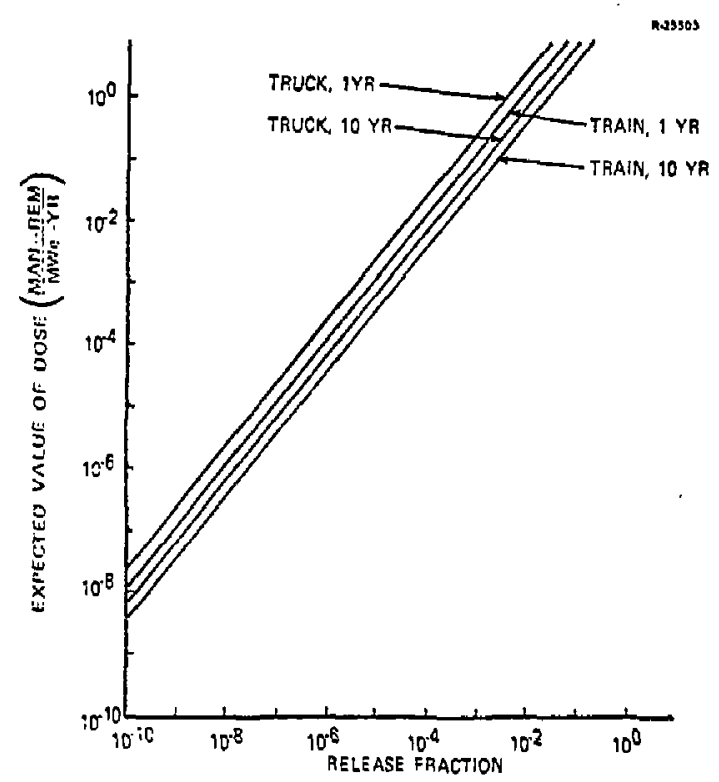

Figure 4.1-6 Sensitivity of Dose to Solid Characteristics: Transportation, Dispersion, Puncture

between the dose from 1-yr old waste and 10-y: old waste is considerably smaller for transportatinn accidents because the age of the waste does not influence the probability of its release.

Insights into acceptable release fractions can also be gained from Figs, $4.1-3$ to $4.1-6$. For example, if $10^{-2}$ to $10^{\circ} \mathrm{Man}-\mathrm{Rem} / \mathrm{MHe}-\mathrm{yr}$ is the range to largest acceptable expected population dose per accident mode, maximum acceptable release fractions for are on the order of $10^{-5}$ to $10^{-3}$ for release by dispersion from truck impact accidents and 
$10^{-3}$ to $10^{-1}$ for train impact accidents. As in the case of drainage of the interim storage pool, the total expected dose is the sum of those from all the accident modes. For example, if truck transportation of $1-\mathrm{yr}$ old waste is considered the total expected dose is the sum of those from impact dispersion, fire dispersion, fire volatiles, puncture dispersion and the water pathway modes discussed below.

Figures 4.1-7 through 4.1-9 illustrate the sensitivity relations for transportation accidents which involve water pathways to the biosphere. They differ slightly from Figs. 4.1-3 to 4,1-6 in the method of presentation. The expected dose shown is to a single individual. The reader must provide an assumed population living in the vicinity of the effected body of water. For example, if 100,000 people are presumed to live near the effected water body the lines must be raised $b_{j}$ five orders of magnitude to represent expected population dost in Man-Rem/MWe-yr. In this case, if $10^{-1}$ Man-Rem/MWe-yr is the largest permissible expected dose from dissolution following an impact accident then the maximum acceptable release fraction for truck transportation is on the order of $5 \times 10^{-4}$ and for train transportation $3 \times 10^{-3}$.

Summary - This section has provided the sensitivity relations developed for the critical accidents which can cause relatively significant expected population dose during the time period prior to sealing the waste repository. The use of these relations to specify solid waste characteristics, as reflected in the fraction of available material released in a modal accident, was demonstrated. It is felt that the Baseline $B$ type solidified waste will result in low enough release fractions in transportation accidents that it will satisfy any reasonable dose criterion. The acceptability of the Baseline A solid requires further study. 


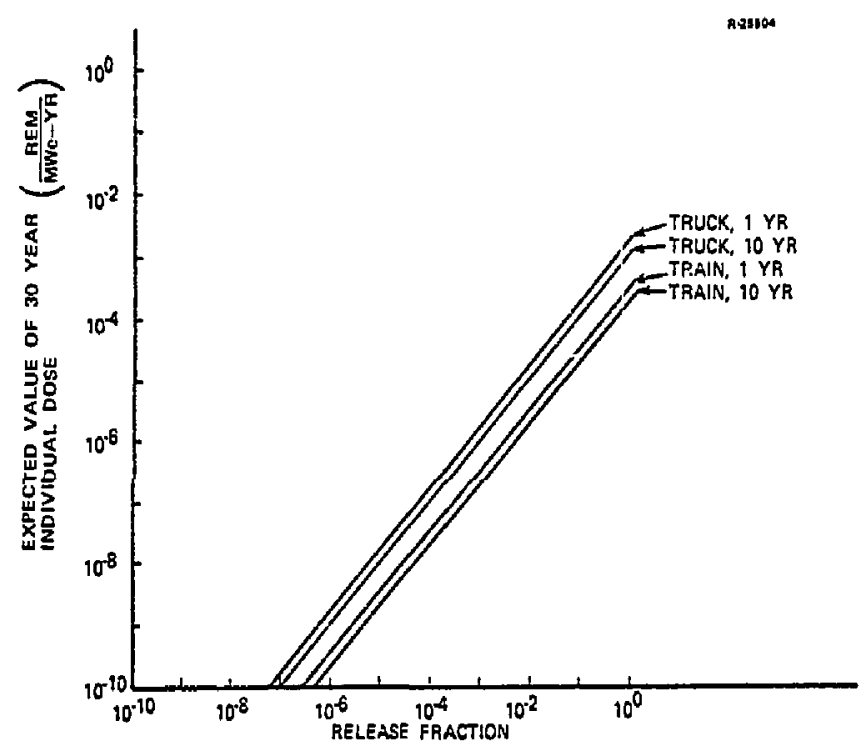

Figure 4.1-7 Sensitivity of Dose to Solid Characteristics: Transportation, Dissolution, Impact

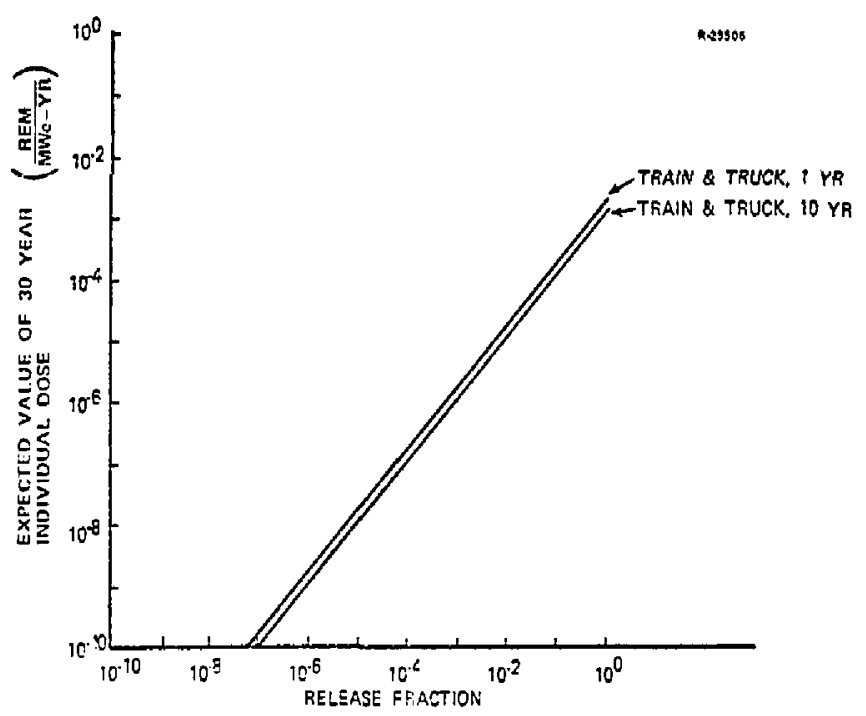

Figure 4.1-8 Sensitivity of Dose to Solid Characteristics: Transportation, Dissolution, Fire 


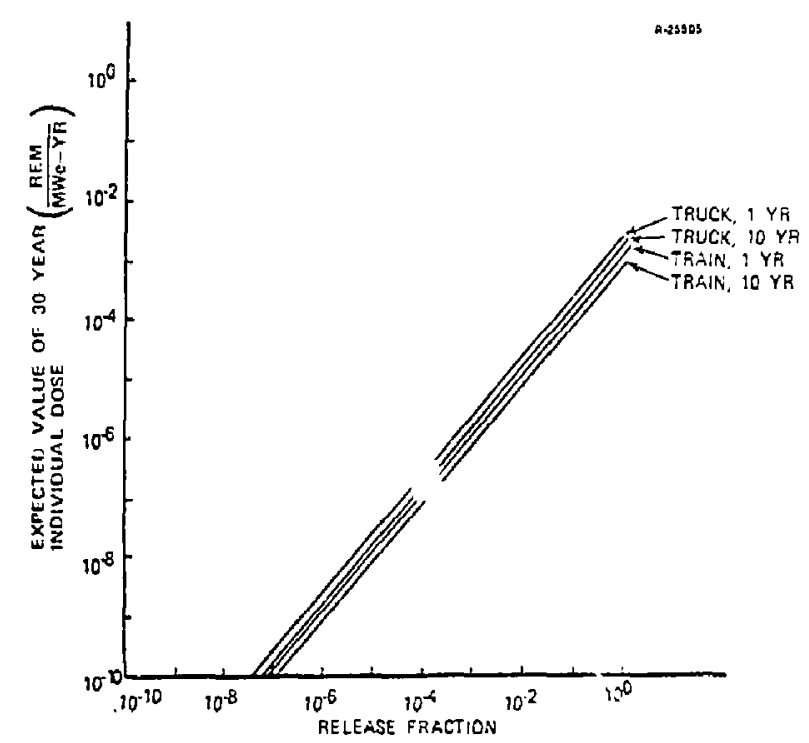

Figure 4.1-Q Sensitivity of Dose to Solid Characteristics: Transportation, Dissolution, Puncture

Additional Sensitivity Calculations - The preceding figures display sensitivity relations between expected dose and the characteristics of high level solidified waste. It may be of interest to determine the sensitivity of expected dose to any number of the assumptions and probabilities stated if Chapter 2 . In most cases this is easily accomplished since the expected dose is linearly related to the parameters used in the calculations; if a probability, transportation distance, etc. doubles, the corresponding expected dose also doubles.

The principal exceptions to the linearity describod above are the end points of the release function curre. Tlis curve is the only nonlinearity in the calculation of expected ralue of material released from each accident rode. 
Of course some nonlinearities reside in the models which relate the expected release to expected dose to individuals and populations.

The purpose of this discussion is to emphasize that the plots contained in this section are of a lot more general value than may initially be percieved. Changes in many of the parameters used in their development will not necessarily require an extensive effort to update the curves.

\subsection{SENSITIVITY ANALYSIS OF THE POST EMPLACEMENT PERIOD}

The mathematical models and parameters described in Se ztions 2.6 and 3.1 were employed in a computer analysis of the expected individual 30-yr dose resulting from release of radicactive materials from the HLSW stored in a sealed refositcry. Only the water pathway described earlier was studied. The analysis was carried out to one million years after sealing the repository. Because time did not permit the full development of computer programs to link the detailed Markov chain described in Section 2.6 to the water pathways model described in Section 3.1, the effects of loss of surface control were not studied. Any type of seismic activity was assumed to result in leaching of waste into the aquifer, but the character of the aquifer was assumed to remait unchanged.

Figure 4.2-1 shows the history of the expected value of 30-yr individual dose from release from the repository as a function of time since emplacement. The plot represents two solubility characteristics -- a leach time of 10,000 years and one of $0.01 \mathrm{yr}$. It can be seen that little difference in individual dose results over this broad range of solubilities. 


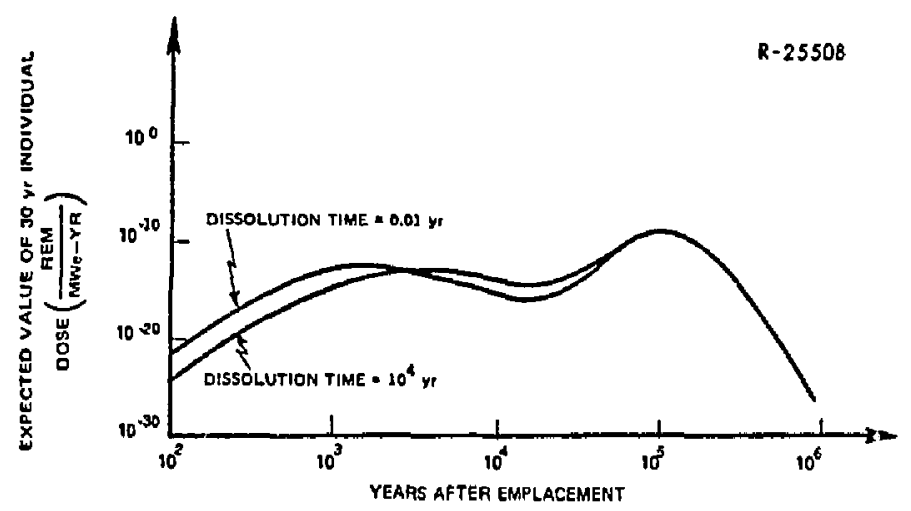

Figure 4.2-1 Expected Value of Individual Dose From Reiease From the Repository

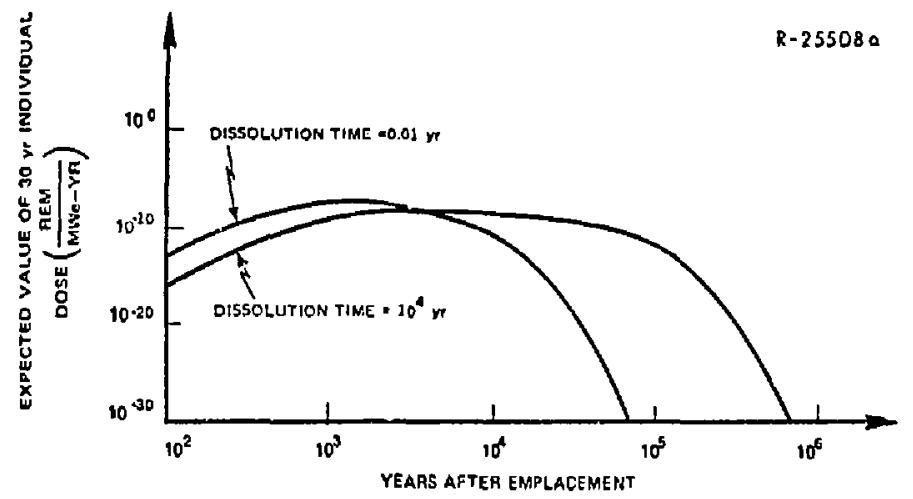

Figure 4,2-2 Expected Value of Individual Dose From Release From the Repository: Ion Exchange process Inhibited 
Two peaks appear in the curves shown in Fig. 4.2-1. The earlier peak results from nuclides whose flow through the aquifer is not inhibited by ion exchange processes -- they move at the same rate as the ground water. In particular, the expected dose due to the nuclide technetium dominates the total expected dose shown out to about 20,000 years. After 20,000 years the slower moving nuclides reach the water system and dominate. For the period 20,000 to $10^{6}$ years radium, assumed to move two orders of magnitude slower than the ground water, dominates. It is interesting to note that radium is a natural daughter product of uranium and would be available in much larger quantities if nuclear power generation did not exist.

In order to compute a population dose, the reader must multiply the appropriate curve or point in Fig. 4.2-1 by an assumed population. The largest individual dose irdicated by Fig, $4.2-1$ is $10^{-9}$ Rem/MWe-yr.

Figure 4.2-2 is included to illustrate the difference in expected individual dose that results if the ion exchange process is absent. In this case all nuclides migrate at the same speed as the ground water. It can be seen that the peak values occur earlier and can be two to three orders of magnitude higher than those in Fig. 4.2-1. The peak for the largest solubility is about one order of magnitude above that of the smaller solubility. The dominant nuclides are, in sequence, ${ }^{90} \mathrm{Sr},{ }^{243} \mathrm{Am}$ and ${ }^{241} \mathrm{Am}$, and ${ }^{226} \mathrm{Ra}$.

Summary - This section has provided the results of sensitivity analysis of the impact of HLSW characteristics on expected radiation dose due to release from the waste repository. It is shown that there is little difference, in terms of maximum individual 30-yr dose, over a wide range 
of dissolution rates. This indicates that the solid waste form is of little importance after the repository is sealed.

The effects of loss of surface control were not included in this study. It is anticipated that the addition of this mode of release will increase the expected dose during the first 1,000 years and decrease it after 10,000 years.

\subsection{CHAPTER SUMMARY}

This chapter has presented the sensitivity curves which are the principal quantitative results of the investigation. It is shown that the age of the waste, between one and ten years after removal from the reactor, is of little consequence in transportation accidents and that the solubility of the solidified waste may be of little consequence once it is sealed in the repository. The use of the models described in Chapters 2 and 3 has been demonstrated by the generation of the results given here. 
5.

CONCLUSIONS AND RECOMMENDATIONS

\subsection{CONCLUSIONS}

From the work reported in this document, several conclusions can be drawn regarding accidental release of radioactive materials subsequent to the solidification of high level waste from power reactors. These conclusions are based on calculations of expected dose to the general population per megawatt electric-year. The chiet nonclusions are:

- Accidents during transportation between the fuel reprocessing plant (FRP) and the final repository and a massive loss o: cooling during interim storage at the FRP provide the dominant contributions to expected dose.

- For the statistical accident data base used, employment of rail transportation provides a somewhat lower expected dose due to transportation accicents then use of trucks.

- Age of the radioactive waste is not a major factor in controlling the expected dose from transportation accidents. The range of ages studied was from one year to tei years since removal from the reactor.

- If a goal of 0.1 Man-REM/MWe-yr is used as the maximum permissible expected dose from that portion of the waste management sequence studied, the Baseline $B$ solid postulated in Chapter 2 is acceptable. The adequacy of the Baseline A solid must be established through further study. 


\subsection{RECOMMENDATIONS}

The study reported here has led to the insights described above. The validity of the expected dose calculations can be improved considerably and additional insights can be gained by refining and expanding both the mathematical models and the sensitivity relations they are instrumental in developing. It is recommended that the following extensions of this investigation be pursued:

- Perfect the data on which release fractions for all types of accidents are based. Uncertainty in stating the release fraction for the identified critical accidents is the largest single contributor to uncertainty in the expected doses computed in the present study.

- Improve knowledge of the statistics of transportation accidents, Since these accidents are major contributors to the expected dose due to accidents, further refinement is necessary. In particular, more up-to-date information on accident rates is needed, severity relations for vehicles whose only cargo is the massive solid waste transportation cask must be sought, and more should be known about the relative frequency and severity of accidents in urban as opposed to rural areas.

- Gather more data on the statistics reiated to post-emplacement events such as earthquakes.

- Continue to develop the model of release from the repository. Terms should be added to the Markov chain model, representing resealing of the repository. These are particularly important to allow analysis of burial in salt deposits. 
- Revise the computer model of release from the repository and exercise it to study the effects of drilling into the aquifer, distance between the rerository and the surface water body that is contaminated, flush rate of the contaminated surface water, water body size and effects when the nuclides released are deposited in major marine bodies of water.

The study reported here has developed a set of useful computer tools and has shown which aspects of the problem studied are most important. It remains to refine those tools and direct them toward a more precise study of the inportant aspects of waste management. 
APPENDIX A

\section{CONCENTRATION EQUATIONS FOR. THE AQUIFER}

The concentration in the repository and shaft (cell 0), corresponding to the mass balance of Fig. 3.1-2, is given by

$$
\begin{aligned}
\frac{d}{d t} C_{j}(0)= & \frac{\lambda_{l}}{V(0)} m_{c_{j}}-\left[\lambda_{j}+\frac{\nu}{K_{j}} \frac{A(0)}{V(0)}+\frac{D}{K_{j}} \frac{A}{\Delta V(0)}\right] C_{j}(0) \\
& +\frac{D}{K_{j}} \frac{A(0)}{\Delta V(0)} C_{j}(1)
\end{aligned}
$$

where

$$
\begin{aligned}
& V(0) \text { is the volume of cell } 0\left(\mathrm{~m}^{3}\right) \\
& \mathrm{A}(0) \text { is the area of the interface between celi } \\
& 0 \text { and cell } 1\left(\mathrm{~m}^{2}\right) \\
& \frac{1}{\mathrm{~K}_{j}} \quad \begin{array}{l}
\text { is the proportion of nuclide } j \text { in the } \\
\text { cell that is mobile in water }
\end{array} \\
& \mathrm{L} \quad \text { is the average distance for mixing }
\end{aligned}
$$

and

$$
{ }^{j} \mathrm{j} \text { is the atomic decay coefficient }\left(\mathrm{a}^{-1}\right)
$$

The mass balance for a typical cell is shown in Fig 3.1-3. ihjs leads to the concentration equation 


$$
\begin{array}{r}
\frac{d}{d t} c_{j}(k)=-\left[\lambda_{j}+a_{j}+(1+R(k)) \beta_{j}\right] c_{j}(k)+ \\
R(k)\left(a_{j}+\beta_{j}\right) C_{j}(k-1)+\beta_{j} C(k-1)
\end{array}
$$

where

$$
\begin{aligned}
& a_{j}=\frac{v}{K_{j} \Delta z}, A(k)=\begin{array}{c}
\text { cross sectional area } \\
\text { of cell } k
\end{array} \\
& \varepsilon_{j}=\frac{D}{K_{j} \Delta z^{2}}, \quad \Delta z=\text { cell length } \\
& R(k)=\frac{A(k-1)}{A(k)}
\end{aligned}
$$

For the last cell (cell $\mathrm{n}$ ), the mass balance is shown in Fig. 3.1-4, and the concentration equation is

$$
\begin{aligned}
\frac{d}{d t} C_{j}(n)=- & {\left[\lambda_{j}+\alpha_{j}+(2+R(n)) \beta_{j}\right] C_{j}(n) } \\
& +R(n)\left[a_{j}+B_{j}\right] C_{j}(n-1)+\frac{2 D}{\Delta z} C_{j} \quad(A-6)
\end{aligned}
$$

It has been assuned here that the distance for diffusion is one-half the cell length $\Delta \mathrm{z}$. 


\section{APPENDIX B \\ CONCENTRATION EQUATIONS FOR WATER, SOIL, AND PEOPLE}

The concentration of nuclide $j$ in the water, given the mass talance shown in Fig. 3.1-6, is given by the first-order ordinary differential equation

$$
\begin{aligned}
& \frac{\partial}{d t} C w_{j}=-\left[\lambda_{j}+\frac{2 D A(n)}{\Delta z V_{w}}+\frac{D A_{S}}{d V_{w}}+\frac{F_{I}+F_{O}}{V_{w}}+N_{p} \cdot \frac{I_{w j}}{V_{w j}}\right] C w_{j} \\
& +\left[\frac{\nu}{K_{j}} \frac{A(n)}{V_{w}}+\frac{2 D A(n)}{\bar{K}_{j} \Delta z V_{W}}\right] C_{j}(n)+\left[\frac{F_{I}+F_{R}}{K_{j} V_{W}}\right] C_{T_{j}} \\
& +\left[\frac{D A_{S}}{K_{j} V_{w} d}\right] C_{S_{j}}+\left[\frac{N_{p} \lambda_{B_{j}}}{V_{W}}\right] C_{p_{j}}
\end{aligned}
$$

where

$$
V_{w}=\text { the volume of the water system }\left(\mathrm{m}^{3}\right)
$$

and the meaning of other notation is as given in Section 3.1.5. Figures 3.1-7 and 3.1-8 show the mass balance for the topsoil and the people. Figure 3.1-9 shows the mass balance for the sediment, subsoil, etc. The concentration equations are: 
For topsoil

$$
\frac{d}{d t} C_{T_{j}}=-\left[h_{j}+\frac{F_{R}+F_{I}}{K_{j}}+N_{T} \frac{I_{T}}{\nabla_{T}}\right] C_{T_{j}}+\frac{F_{I}}{\nabla_{T}} C w_{j}(B-2)
$$

where

$$
V_{T}=\text { the volume of topsoil }\left(\mathrm{m}^{3}\right)
$$

For people

$$
\frac{d}{d t} C_{p_{j}}=-\left[\lambda_{j}+\lambda_{B_{j}}\right] C_{P_{j}}+I_{T_{j}} C_{T_{j}}+I_{W_{j}} C_{W_{j}}
$$

For sediment, subsoil, etc.

$$
\frac{d}{d t} C_{s_{j}}=-\left[\lambda_{j}+\frac{D A_{s}}{K_{j} V_{s} d}\right] C_{s_{j}}+\left[\supset \frac{A_{s}}{V_{s}}\right] C_{j}
$$

where

$$
V_{S}=\text { the volume of sediment and subsoil }\left(\mathrm{m}^{3}\right)
$$


APPENDIX C

EQUATIONS FOR NUCLIDE INTAKES

The effective rate at which a person takes in nuclide j from water is

$$
\operatorname{IW}(j)=\operatorname{DWI}(j)+\operatorname{AFI}(j)+\operatorname{VI}(j)+\operatorname{DAPI}(j)
$$

where

$$
\begin{aligned}
& \operatorname{DWI}(j)=\text { drinking water intake }(\ell / \mathrm{yr}) \\
& \operatorname{AFI}(j)=\text { aquatic food intake }(\ell / \mathrm{yr}) \\
& \operatorname{VI}(j)=\text { vegetable intake }(\ell / \mathrm{yr}) \\
& \operatorname{DAPI}(j)=\text { domestic animal product intake }(\ell / \mathrm{yr})
\end{aligned}
$$

The aquatic food intake is

$$
A F I(j)=B F(j) F C+B C(j) C C+B M(j) M C
$$

where

$$
\begin{aligned}
& B F(j), B C(j), B M(j)=B i o l o g i c a l \text { conversion } \\
& \text { factors }\left(\frac{\mathrm{C} i / \mathrm{Kg}}{\mathrm{Ci} / \mathrm{h}}\right) \text { for fish, } \\
& \text { crustacea, and mollusc } \\
& \text { FC, } C C, M C=\text { fish, crustacea, and mollusc } \\
& \text { consumption }(\mathrm{Kg} / \mathrm{yr})
\end{aligned}
$$

The vegetable intake is

$$
V I(j)=\sum_{k=1}^{9} C V(j, k) V C(k)
$$


where

$$
\begin{aligned}
& \begin{aligned}
C V(j, k)= & \text { the concentration factor }(\mathrm{Ci} / \mathrm{Kg} / \mathrm{Ci} / \mathrm{l}) \\
& \text { for nuclide } \mathrm{j} \text { in vegetable } \mathrm{k}
\end{aligned} \\
& \begin{aligned}
& V C_{k} \quad \begin{array}{l}
\text { yearlg consumption }(\mathrm{Kg} / \mathrm{yr}) \text { of } \\
\text { vegetable } \mathrm{k}
\end{array} \\
& C V(j, k)=\operatorname{IR}(\mathrm{k}) \frac{\mathrm{T}(\mathrm{k})}{\mathrm{V}(\mathrm{k})}
\end{aligned}
\end{aligned}
$$

where

$$
\begin{aligned}
& I R(k)=\text { the irrigation rate }\left(l / m^{2} \text {-day }\right) \\
& \text { during the growing season for } \\
& \text { vegetable } \mathrm{k} \\
& T \text { (k) accounts for translocation from } \\
& \text { plant surface to edible portion } \\
& \text { (day) } \\
& V(k)=\text { yield }\left(K_{E} / m^{2}\right)
\end{aligned}
$$

The domestic animal product intake is

$$
\operatorname{DAPI}(j)=\sum_{L=1}^{5} C A(j, L) A C(L)
$$

where

$$
\begin{aligned}
C A(j, L)= & \text { the concentration factor (Ci/unit } / \mathrm{Ci} / \ell) \\
& \text { for nuclide } j \text { in animal product } L \\
A C(L)= & \text { yearly consumption of animal product } L \\
& (\text { unit/yr) }
\end{aligned}
$$

The concentration factors are

$$
C A(j, L)=S(j, L)[C F(j, L) Q(L)+Q W(L)]
$$


where

$$
\begin{aligned}
S(j, L)= & \text { transfer coefficient (Ci/unit/Ci/day) } \\
C F(J, L)= & \text { concentration factor for feed } \\
& (\mathrm{Ci} / \mathrm{Kg} / \mathrm{C} / \mathrm{l}) \\
\mathrm{QH}(\mathrm{L})= & \text { water consumption }(\ell / \text { day }) \\
Q(L)= & \text { feed consumption }(\mathrm{Kg} / \text { day })
\end{aligned}
$$

The intake from the topsoil is

$$
I T(j)=B(j) \quad\left[\sum_{k=1}^{9} V C(k)+\sum_{L=1}^{5} S(j, L) Q(L) A C(L)\right] / D_{T}
$$

where

$$
\mathrm{D}_{\mathrm{T}}=\text { the density of the topsoil }\left(\mathrm{Kg} / \mathrm{m}^{3}\right)
$$

and

$$
B(j)=\text { plant concentration factor }(\mathrm{Ci} / \mathrm{Kg} / \mathrm{Ci} / \mathrm{Kg})
$$




\section{REFERENCES}

1. Reactor Safety Study, An Assessment of Accident Risks in U.S. Commercial Nuclear Power Plants, WASH-1400, U.S. Nuclear Regulatory Commission, October 1975.

2. Schneider, K.J., and Platt, A.M., Ed. "High-Level Radioactive Waste Management Alternatives", Battelle Pacific Northwest Laboratories, BNWL-1900, May 1974.

3. Clarke, R.K., Foley, J.T., Hartman, W.F., and Larson D.W., "Severities of Transportation Accidents," Sandia Laboratories, SLA-74-0001, September 1975 (Review Copy).

4. NUREG-0034, "Draft Environmental Statement on the Transportation of Radioactive Material by Air and Other Modes," U.S. Nuclear Regulatory Commission, March 1976.

5. Brobst, W.A., "The Probability of Transportation Accidents," Department of Defense Explosives Safety Board, 14 th Annual Explosives Safety Seminar, New Orleans, 10 November 1972.

6. Langhaar, "Radioactive Materials Transport Experience, International Symposium on the Management of Wastes from the LWR Fuel Cycle," Denver, Colorado, July 1976.

7. NRC Regulations 10 CFR Part 71 .

8. "Regulations for the Safe Transport of Radioactive Materials," IAEA Safety Series No. 6, Vienna, Austria, 1967.

9. Richter, C.F., Elementary Seismology, W.H. Freeman Company, San Francisco, 1958 .

10. Press, F. and Siever, R., Earth, W.H. Freeman Company, San Francisco, 1974.

11. Bollinger, G.A., "Historical and Recent Seismic Activity in South Carolina", Bulletin of Seismological Society of American, Vol. 62, No. 3, June 1072 .

12. Algermissen, S.T., "Seismic Risk Studies in the United States", Proc. of the 4th International Conference cn Earthquake Engineering, Santiago, Chile, 1969. 


\section{REFERENCES (Continued)}

13. Bureau of Mines Circular $\# 57$.

14. Katz, D.L. and Coats, K.H., Underground Storage of Fluids, U. of Michigan, Ann Arbor, MI., 1968.

15. U.S. Bureau of the Census, Statistical Abstract of the United States, $92^{\text {nd }}$ edition, Tashington, D.C., 1971.

16. The National Atlas of the United States, U.S. Department of the Interior, Geological Surveg, Washington, D.C., 1970.

17. "Forecast/Review", Oil and Gas Journal, Jan. 29, 1973.

18. "Reactor Safety Study", U.S. Nuclear Regulatory Commission, WASH-1400, October 1975.

19. Blake, V.E., "A Prediction of Hazards from the Random Impact of Meteorites in the Earth's Surface", Sandia Labs, Aerospace Nuclear Safety, SC-RR-68-388, December 1968.

20. Burkholder, H.C., et. al., "Incentives for Partitioning High-Level Waste," Battelle Pacific Northwest Laboratories, BNWL-1927, November 1975.

21. Handbook of Chemistry and Physics, 49th edition.

22. Peterson, K., "Meteorological Part of Pathways Chapter for Nuclear Waste Management Report," Lawrence Livermore Laboratories internal memorandum USAG76-24, 22 September 1976. asstimes any lesal tiabilisy of responsibility of any accuracy, completeness or uroduct of process information, apparatus, product or process disclosed, or represents that lis infringe privately-owned sights." 